\title{
El Ordovícico Medio del Anti-Atlas marroquí: paleobiodiversidad, actualización bioestratigráfica y correlación
}

\section{The Middle Ordovician of the Moroccan Anti-Atlas: Paleobiodiversity, biostratigraphic review and correlation L'Ordovicien moyen de l'Anti-Atlas marocain : paléobiodiversité, révision biostratigraphique et corrélation}

\author{
Juan Carlos Gutiérrez-Marco ${ }^{\mathrm{a}, *}$, Jacques Destombes ${ }^{\mathrm{b}}$, Isabel Rábano ${ }^{\mathrm{c}}$, \\ Guillermo Federico Aceñolaza ${ }^{d}$, Graciela Noemí Sarmiento ${ }^{a}$, Miguel Ángel San José ${ }^{a}$ \\ a Instituto de Geología Económica (CSIC-UCM), \\ Universitad Complutense, Facultad de Ciencias Geológicas, 28040 Madrid, Espagne \\ b 19, rue de-la-Fon-de-Madran, 33600 Pessac, France \\ ${ }^{c}$ Museo Geominero, Instituto Geológico y Minero de España, Ríos Rosas 23, 28003 Madrid, \\ Espagne \\ ¿ Instituto Superior de Correlación Geológica (CONICET-UNT), Miguel Lillo 205, 4000 Tucumán, \\ Argentine
}

\begin{abstract}
Resumen
Las formaciones del Ordovícico Medio del Anti-Atlas (sur de Marruecos) han librado un variado registro de trilobites, moluscos, equinodermos, braquiópodos, graptolitos, microfósiles e icnofósiles en alrededor de 180 localidades. Gran parte de ellas fueron descubiertas durante la realización de la cartografía geológica a escala 1:200.000 y la mayoría del material paleontológico permanece inédito. En este trabajo se revisa el marco geológico de todas las localidades fosilíferas conocidas (tanto las publicadas como las inéditas), poniéndose en evidencia numerosas discrepancias litoestratigráficas en relación con estudios precedentes. Además de la reevaluación estratigráfica, se revisa el contenido paleontológico de cada formación y localidad, actualizando la taxonomía de muchas de las formas identificadas. Desde el punto de vista cronoestratigráfico, el conjunto de la Formación Tachilla y las cinco formaciones del Grupo Primer Bani se adscriben por vez primera a la escala regional mediterránea. Los límites Oretaniense-Dobrotiviense y Dobrotiviense-Berouniense se sitúan, respectivamente, en la Formación de Bou-Zeroual y en el techo de la Formación Izegguirene. El tránsito Oretaniense inferior-superior se emplaza provisionalmente en el tercio superior de la Formación Tachilla, y el límite Dobrotiviense inferior-superior hacia la base o en la parte inferior de la Formación Ouine-Inirne. También se aporta la correlación general de las unidades del Ordovício Medio antiatlásico con respecto a la escala estándar o global del sistema Ordovícico. La base de la Serie Ordovícico Superior se sitúa probablemente en la parte inferior de la región como un centro importante de diversificación para numerosas faunas mediterráneas, las cuales experimentan una amplia dispersión posterior en las plataformas marinas del norte de Gondwana.
\end{abstract}

\footnotetext{
Abstract

Middle Ordovician formations of theAnti-Atlas ranges of southern Morocco provided a diverse record of trilobites, molluscs, echinoderms, brachiopods, graptolites and micro- and ichnofossils from about 180 fossil localities. These were mainly found during the national geological mapping to the 1:200.000 scale, and most of them remained unreferenced until now. The lithostratigraphic position of all fossil localities is
} 
briefly studied showing, in some cases, noteworthy discrepances with previous works. Besides this stratigraphical reappraisal, a review of the fossil record for each formation and locality is done, together with a taxonomical update. From a chronostratigraphical point of view, the whole sucession constituted by the Tachilla Formation and First Bani Group formations are here referred to the Mediterranean regional scale. The Oretanian-Dobrotivian and Dobrotivian-Berounian boundaries are located respectively in the Bou-Zeroual Formation and at the top of the Izegguirene Formation. The transition between the lower and upper Oretanian is provisionally established in the upper third of the Tachilla Formation, and those between the lower and upper Dobrotivian at the base or in the lower part of the Ouine-Inirne Formation. A general correlation with the global standard and British regional scales is also suggested for the Middle Ordovician of the Moroccan Anti-Atlas. The basal limit of the Upper Ordovician series probably lies within the lower part of the Izegguirene Formation. Paleobiogeographical data confirm the interest of this area as an important diversification center for many Mediterranean faunas that underwent remarkable dispersal in northern Gondwanan shelves.

\section{Résumé}

Les formations de l'Ordovicien moyen des montagnes de l'Anti-Atlas, dans le sud-marocain, ont livré des trilobites, des graptolites, des brachiopodes, des échinodermes, des mollusques, des micro- et ichnofossiles dans environ 180 localités. Elles ont été principalement découvertes lors du levé des cartes géologiques au $200000^{\mathrm{e}}$ et une importante quantité de ce matériel reste encore non publiée. La situation géologique de toutes ces localités fossilifères est brièvement examinée, montrant notamment dans quelques cas des désaccords avec les études antérieures. A côté de la réévaluation stratigraphique, une révision du contenu paléontologique pour chaque formation et chaque localité est faite ainsi que sa mise à jour taxonomique. D'un point de vue chronostratigraphique, l'entière succession de la Formation du Tachilla et les cinq formations du Groupe du 10 Bani sont ici réferrés à l'échelle régionale méditerranéenne. Les limites Oretanien-Dobrotivien et Dobrotivien-Berounien sont respectivement placées dans la Formation de Bou-Zeroual et au sommet de la Formation d'Izegguirene. La transition entre l'Oretanien inférieur et supérieur est provisoirement située au tiers supérieur de la Formation du Tachilla et celle entre le Dobrotivien inférieur et supérieur est provisoirement située à la base ou dans la partie inférieure de la Formation de Ouine-Inirne. Une corrélation générale avec les échelles régionales britanniques et l'échelle standard globale est aussi suggérée pour l'Ordovicien Moyen de l'Anti-Atlas marocain. La limite basale des séries de l'Ordovicien supérieur se situe probablement à l'intérieur de la partie inférieure de la Formation d'lzegguirene. Les données paléobiogéographiques confirment la valeur de cette région comme un centre important de diversification pour de nombreuses faunes méditerranéennes qui subirent une remarquable dispersion dans les plates-formes du Gondwana septentrional.

Palabras clave: Ordovícico; Darriwiliense; Bioestratigrafía; Biodiversidad; Correlación; Marruecos

Keywords: Ordovician; Darriwilian; Biostratigraphy; Biodiversity; Correlation; Morocco

Mots clés : Ordovicien ; Darriwilien ; Biostratigraphie ; Biodiversité ; Corrélation ; Maroc

\section{Introducción y antecedentes}

Los materiales ordovícicos presentes en la cadena monta-ñosa del Anti-Atlas (Marruecos meridiona: Fig. 1) compo-nen la sucesión africana más completa y representativa de este periodo, entre todas aquéllas formadas en el margen meridional del antiguo continente de Gondwana.

La investigación del Ordovícico del Anti-Atlas tuvo su inicio en el primer tercio del presente siglo (Bigot y Dubois, 1931; Choubert, 1942, 1943), pero sólo a partir de 1959 comenzó a adquirir relevancia gracias a la aportación fundamental de uno de los autores (J.D.), cuyas exploraciones cartográficas, estratigráficas, paleontológicas y mineras sentaron las bases del conocimiento actual, y continúan siendo fuente primordial de inspiración de muchos estudios paleontológicos. La mayor parte de estos últimos han sido realizados, o están en elaboración, a partir de sus muestras y locali-dades originales: los estudios aparecidos más recientemente con muestras de Destombes son, por ejemplo, las mono-grafías de Vidal (1996, 1998b) y Horný (1997b).
Los materiales del Ordovícico Medio del Anti-Atlas se inscriben en dos grandes conjuntos litoestratigráficos. El inferior, con predominio pelítico (Formación Tachilla), constituye la unidad terminal del denominado Grupo Pizarroso de las Feijas Externas. El superior, donde dominan los tramos gruesos de areniscas separados por otros subordina-dos de pizarras micáceas y arenosas forma, en su conjunto, el llamado Grupo de Areniscas del Primer Bani, subdividido (de muro a techo) en las formaciones Taddrist, Bou-Zeroual, Guezzart, Ouine-Inirne e Izegguirene. La definición y exten-sión de todas estas unidades (dos grupos y seis formaciones), así como los detalles básicos de cada una, estratigráficos y sedimentológicos, fueron compilados por Destombes (in Destombes et al., 1985), y no es necesario reiterarlos en la presente nota. En la Fig. 2 se presentan aspectgs geperales de campo de algunos afloramientos impottantes.

De un modo bastante paradójico, este importante conjunto litoestratigráfico del Ordovícico Medio anti-atlásico, reúne también las unidades peor conocidas desde los puntos de vista paleontológico y bioestratigráfico, de cuantas brindan 


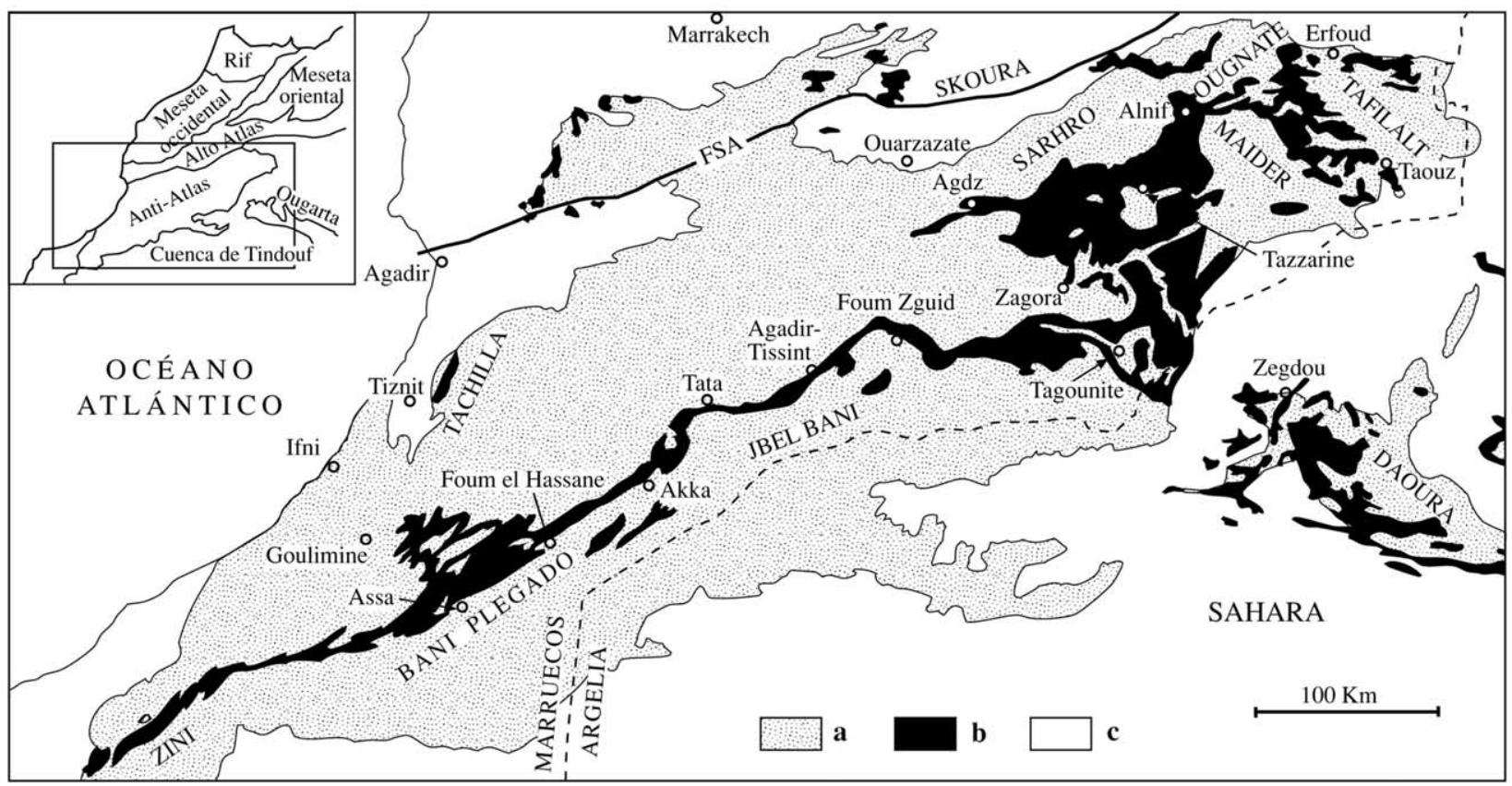

Fig. 1. Esquema geológico del Anti-Atlas, mostrando la situación de las principales regiones y afloramientos fosilíferos del Oretaniense y Dobrotiviense, mencionados tanto en el texto como en el apéndice (mapa modificado de Destombes in Destombes et al., 1985). La frontera argelino-marroquí (todavía e $n$ discusión) ha sido adaptada de la cartografía Michelin ( $n^{\circ}$ 959, 4a ed. 1998). Tramas: a, A floramientos precámbricos y paleozoicos; b, rocas ordovícicas; c materiales postpaleozoicos. FSA, Falla Sur-Atlásica, que sirve de límite a los dominios del Alto Atlas (al norte) y Anti-Atlas (al sur). Fig. 1. Geological sketch map of the Moroccan Anti-Atlas, modified from Destombes (in Destombes et al., 1985), showing the location of the main areas with Oretanian y Dobrotivian fossils mentioned in the text y listed in the appendix. The Moroccan-Algerian border (still under discussion) has been adapted from the Michelin road-map N 959 (4th. ed. 1998). Symbols: a, Precambrian y Palaeozoic rocks; b, Ordovician rocks; c, Post-Palaeozoic cover. FSA, South Atlas Fault, a major geological structure separating the High Atlas (north) from the Anti-Atlas (south).

el rico acervo fosilífero del Ordovícico marroquí. Este concierne esencialmente a las asociaciones fosilíferas del Ordovícico Superior (Grupos Ktaoua y Segundo Bani, con enorme diversidad y originalidad taxonómica) y, en menor medida, a las unidades del Ordovícico Inferior (Pizarras de Fezouata s.I.): ver Destombes et al. (1985) y Vidal (1996, 1998b) para referencias previas. Por contraste, el conjunto litológico del Ordovícico Medio es mucho menos fosilífero, con predominio de paleoambientes energéticos $y$ sedimentos detríticos gruesos, por lo que cuenta también con menores antecedentes de estudio. Pese a ello, las investigaciones es-tratigráficas de uno de los autores (J.D.), proseguidas sis-temáticamente a lo largo de más d e 30 a ños, han logrado inventariar más de 130 localidades $u$ horizontes fosilíferos, de los que aproximadamente un $28 \%$ corresponde a la For-mación Tachilla y el resto (95 puntos) al Grupo Primer Bani. En este cómputo porcentual se incluyen además los escasos yacimientos descubiertos por autores previos (vv.aa. in Termier y Termier, 1950a-c).

Los principales antecedentes paleontológicos, relativos al Ordovícico Medio del Anti-Atlas, se desglosan en estudios parciales sobre trilobites (Destombes, 1966, 1972; Henry y Destombes, 1991), equinodermos (Termier y Termier, 1950c; Chauvel 1966, 1969, 1971, 1978; Paul y Kesling, 1968; Cripps, 1990; Beisswenger, 1994), braquiópodos articulados (Havlíček, 1970, 1971), hiolítidos (Marek, 1983), bivalvos y rostroconchas (Termier y Termier, 1950b; Babin y Destom-bes, 1990), gasterópodos y tergomiidos (Horný, 1997a, b), revisiones modernas sobre microfósiles de pared orgánica (Cramer y Díez, 1975; Elaouad-Debbaj 1984, 1987) y contribuciones puntuales de conodontos (El Bourkhissi y Sarmiento, 1997) u ostrácodos (Gutiérrez-Marco et al., 1997).

Con todo, los estudios citados muestran discrepancias notorias en cuanto a la datación o adscripción estratigráfica de determinados yacimientos que, en trabajos sucesivos de varios, o incluso de un mismo autor, resultan asignados a formaciones distintas, a veces ocupando posiciones dispares en la columna general. Estas anomalías han generado una gran incertidumbre en cuanto a la correlación del Ordovícico del_Anti-Atlas (Fig. 4), ampliada también por la obsolescentcia de la clasificación cronoestratigráfica utilizada, que por nuestra parte solventamos adoptando la escala patrón medi-terránea, definida en Bohemia (República Checa) y España: ver Havlíček y Marek (1973), Havlíček y Fatká (1992), Fatká et al. (1995) y GutiérrezMarco et al. $(1995,2002)$ para referencias previas y discusión general.

El presente trabajo trata pues, de presentar una primera revisión bioestratigráfica del Ordovícico Medio (Formación Tachilla y Grupo Primer Bani), armonizando y actualizando todos los datos paleontológicos hasta ahora publicados, así como otros inéditos. Éstos proceden, principalmente, de una serie de memorias parciales e impublicadas del Mapa Geoló-gico del Anti-Atlas a escala 1:200.000 (Destombes, 1983a-c, 1985, 1987-1988, 2000-2002), donde se detallan y revisan los aspectos estratigráficos de un gran número de yacimien-tos fosilíferos. 

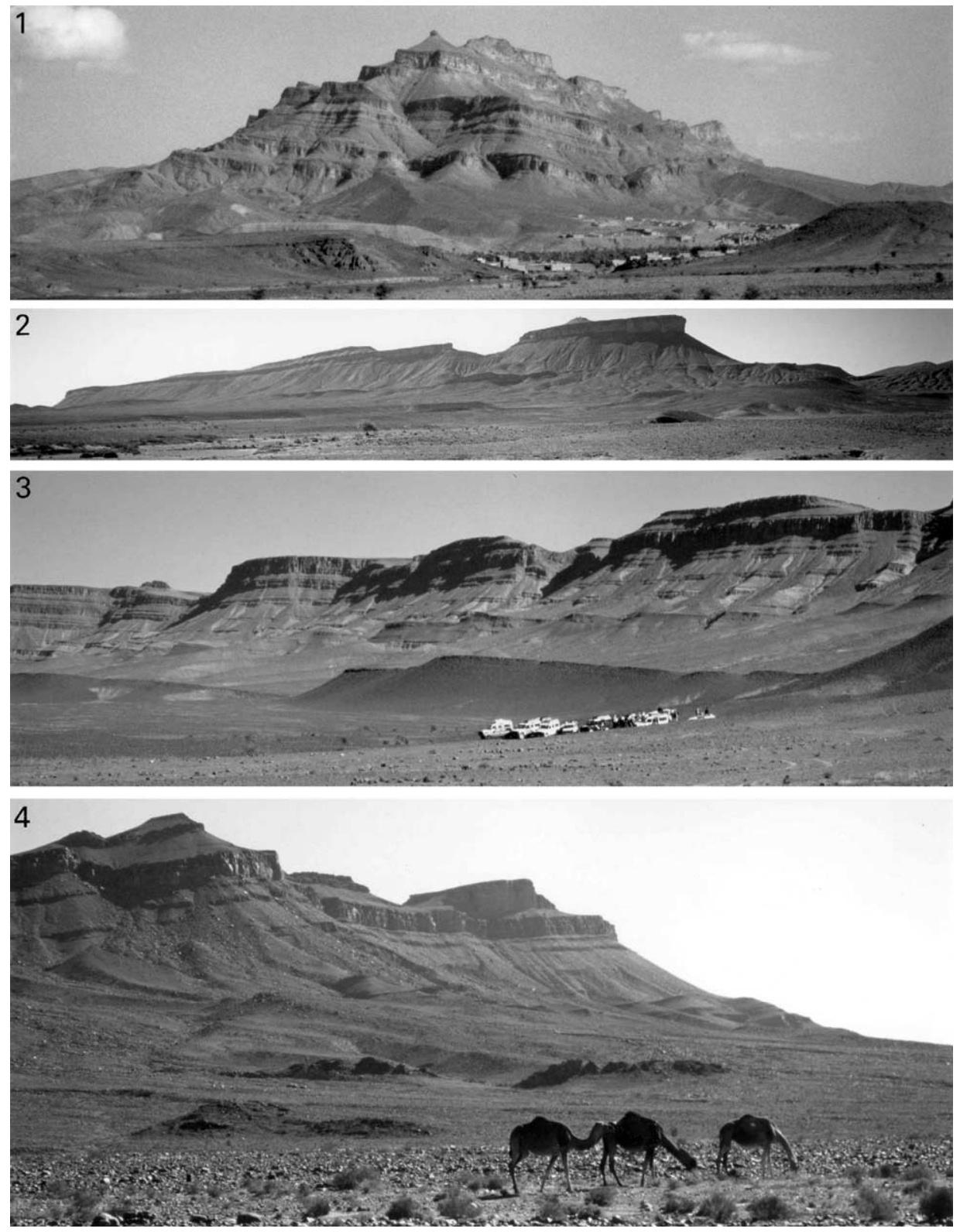

Fig. 2. Algunos aspectos de campo de los afloramientos del Ordovícico Medio en el Anti-Atlas central. 1: Detalle de la sucesión del Grupo Primer Bani en el extremo occidental del Jbel Kissane (1531 m), al ENE de Agdz. Las cuatro crestas cuarcíticas principales corresponden, de abajo a arriba, a las formaciones Taddrist, Bou-Zeroual + Guezzart, Ouine-Inirne e Izegguirene. 2: Vista panorámica del Jbel Talrhoumt al E de Tazzarine mostrando, sobre la llanura formada por las pizarras de la Formación Fezouata Superior (en primer término), el relieve correspondiente al hierro oolítico que define la base de la Fm. Tachilla. A media ladera se aprecia un segundo horizonte ferruginoso ("Nivel Ferruginoso de Tourza"), marcadamente lenticular, que señala la base del Grupo Primer Bani, al cual corresponde también el relieve cuarcítico superior. 3: Panorámica del Jbel Rhart, al NE de Zagora. La planicie inferior corresponde a las pizarras de la Formación Fezouata Superior; le siguen las cuarcitas del Arenig de la Formación Zini (primer relieve pronunciado, detrás de los coches); sobre ella se dispone la Formación Tachilla (ladera de pizarra en la base de la alineación montañosa principal) y, tras el horizonte de hierro oolítico basal (nivel oscuro a media ladera), el conjunto se ve coronado por varias crestas cuarcíticas de las formaciones del Grupo Primer Bani. 4: Tizi n'Tafilalt al ENE de Zagora. Detalle tomado al sur del Jbel Rhart, con afloramientos de las formaciones Tachilla (planicie con dromedarios, en primer término), Taddrist (crestas delgadas a pie de ladera) y relieves abruptos de las formaciones del Grupo Primer Bani. Fig. 2. Panoramic views of Middle Ordovician outcrops in the central Anti-Atlas (Morocco). 1: Stratigraphic sequence of several formations of the First Bani Group in the western part of Jbel Kissane $(1,531 \mathrm{~m})$, ENE of locality of Agdz. The main quartzitic beds correspond, from the base of the mountain to the summit, to the Taddrist, Bou-Zeroual + Guezzart, Ouine-Inirne and Izegguirene Formations. 2: Jbel Talrhoumt, E of Tazzarine. Above the siltstones of the Upper Fezouata Formation (foreground), a first oolithic ironstone bed (base of the Tachilla Formation) can be recognized. Towards the middle part of the hill, a second and remarkably lenticular oolithic ironstone is observed. The Tourza iron ore bed forms the base of the First Bani Group, seen at the topmost part of the cliff. 3: Jbel Rhart, NE of Zagora. The basal plain with the cars is the Upper Fezouata Formation, topped by the Zini Formation, a thin quartzitic unit roughly equivalent to the Armorican Quartzite. Above this, the Tachilla Formation is overlain by the basal ironstone bed of the First Bani Group (black level towards the center of the slope). The remaining streches, made up by several quartzitic formations of the same Group, form the main heights of Jbel Rhart. 4: Tizi n'Tafilalt pass, ENE of Zagora, southern part of Jbel Rhart. Outcrops of Tachilla Formation (foreground with dromedaries) and quartzitic formations of the First Bani Group. 


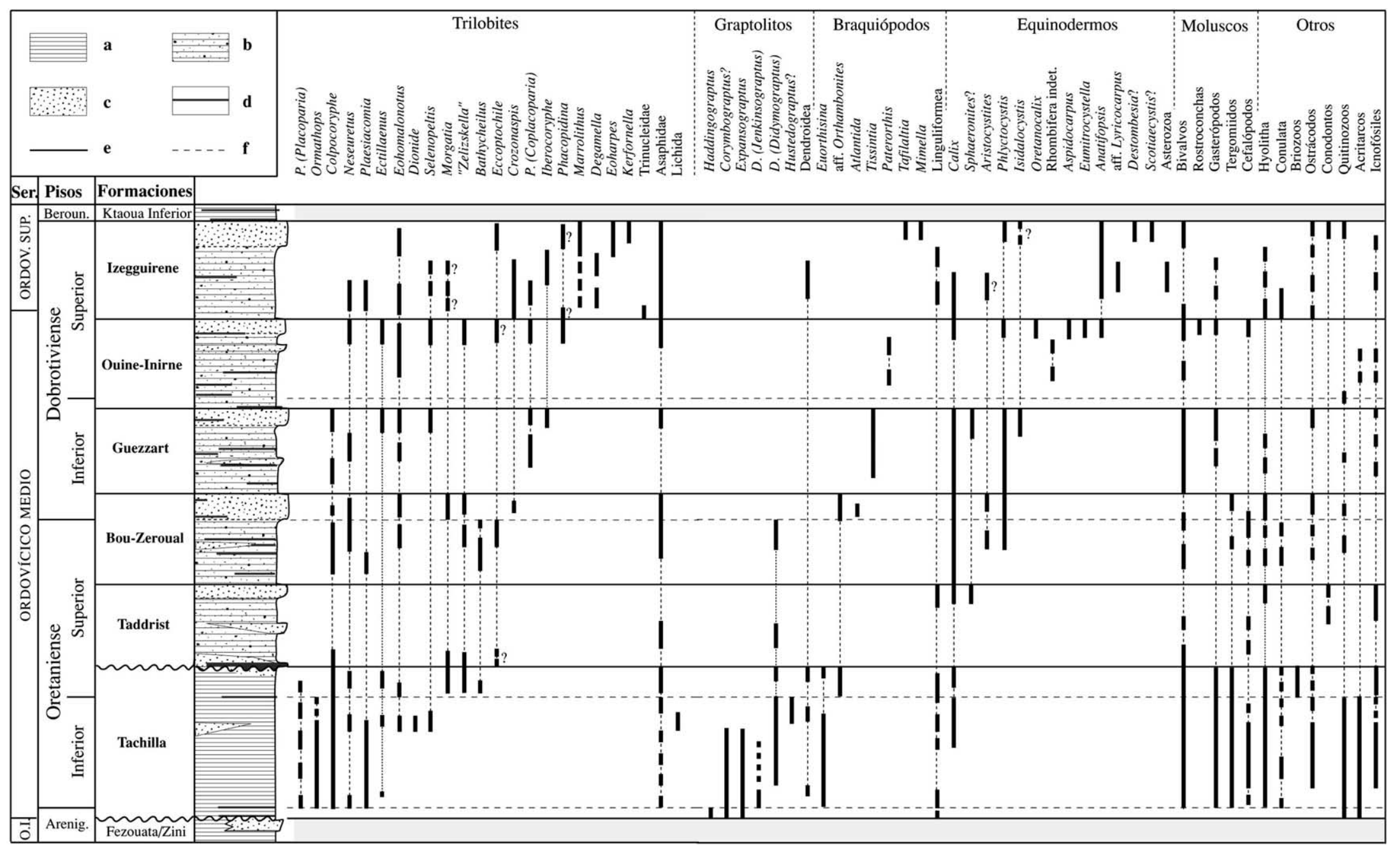

Fig. 3. Distribución estratigráfica de los principales géneros y grupos de invertebrados del Ordovícico Medio del Anti-Atlas. Las especies correspondientes se detallan en el texto, así como los criterios biocronológicos utilizados para la delimitación de unidades cronoestratigráficas en la escala regional nord-gondwaniense. Litologías predominantes y otros símbolos: a, pizarras; b, pizarras arenosas y micáceas; c, areniscas y cuarcitas; d, horizontes de hierro oolítico; e, I ímite litoestratigráfico (concordancia o disconformidad); f, I ímite cronoestratigráfico.

Fig. 3. Generalized stratigraphical scheme of the studied part of the Ordovician sucession of the Moroccan Anti-Atlas, showing the distribution of the main invertebrate groups and genera. Records at the species level, as well as biochronological criteria used for correlation ofregional chronostratigraphic units, are detailed in the text. The symbols for themain lithologies and boundaries are: a, shales; b, sandy and micaceous shales; $\mathbf{c}$, sandstones and quartzites; $\mathbf{d}$, oolithic ironstone beds; $\mathbf{e}$, lithostratigraphic boundary (being conformable or in disconformity); $\mathbf{f}$ chronostratigraphic boundary. 


\section{El registro paleontológico}

En el siguiente listado de fósiles, desglosado por unidades litoestratigráfic a s o I ímites en discusión de unidades, los números que siguen a cada taxón representan la localidad o localidades concretas de su hallazgo. Tales números corres-ponden al inventario personal de uno de los autores (J.D.), asumido por el Servicio Geológico de Marruecos y referido en la mayor parte de las publicaciones paleontológicas. La ubicación geográfica precisa de cada yacimiento se señala en el Apéndice 1, y ambos listados (taxonómico y de localida-des) componen la base de datos paleontológica más completa y actualizada del Ordovícico Medio del Anti-Atlas disponi-ble hasta el momento.

La distribución estratigráfica de los taxones de nivel genérico más importantes y significativos de las formaciones analizadas, se expresa en la Fig. 3. En la relación detallada de fósiles que brindamos seguidatmente, un asterisco $\left(^{*}\right)$ asociado a un número de localidad indica, grosso modo, que ésta corresponde a la base o tercio inferior de la formación e $\mathrm{nl}$ a que se ha encontrado ese taxón concreto. Del mismo modo, el doble asterisco $\left({ }^{* *}\right)$ revela un horizonte situado en el tercio superior de la unidad respectiva. El símbolo en cruz $(+)$, vinculado a un yacimiento concreto, indica que éste consti-tuye la localidad y estratotipo del taxón correspondiente, definido originalmente en el Anti-Atlas. Las identificaciones taxonómicas entre comillas son, en principio, dudosas y requieren una revisión pormenorizada.

Note: Palaeontological localities are described in the Appendix. In the following lists of fossils for each forma-tion, this legend applies: $\left({ }^{*}\right)=$ fossil locality positioned at the base or in the lower third of the corresponding lithos-tratigraphic unit; $\left({ }^{* *}\right)=$ fossiliferous level at the top or in the upper third of the corresponding lithostratigraphic unit; $(+)=$ locality and stratotype of corresponding taxa.

\subsection{Formación Tachilla}

- Trilobites: Ormathops clariondi DESTOMBES $\left(1050^{*}, 1065^{*}\right.$, $\left.1213,1218,1236^{*}, 1528,1320+, 1325,1347,1363,1385\right)$, Phacopina inc. gen. DESTOMBES, 1972 (1510), Colpocoryphe sp. $\left(168^{* *}, 573^{* *}, 1050^{*}, 1065^{*}, 1213,1218\right.$, $1236^{*}, 1247,1320,1325,1347,1363,1385,1419,1570^{\star}, 1575$, 1793, 1873), Neseuretus attenuatus (GIGOUT) (563*), Neseuretus sp. (1873), Plaesiaco-mia sp. $\left(563^{*}, 1050^{*}\right.$, 1065*, 1325?), Eohomalonotus sp. (1873), Placoparia $(P$.$) cambriensis HICKS \left(1065^{\star}\right)$, Placoparia sp. (168**, $\left.441^{*}, 729^{*}, 1050^{*}, 1320,1347,1363,1524,1528,2028\right)$, Ectillaenus sp.(168**, 1873), Illaenidae $\left(1050^{*}, 1213,1230\right.$, 1236, 1320 y 1325 - "Dysplanus?" sp.-, 1347, 1524, 1793), "Ogygiocaris" sp. (436*), Asaphidae (52*, 563*; 1050*, $1213,1236^{*}, 1320,1347,1363,1385,1419,1528-3$ formas distintas-, 1575, 1793, 1794, 1873, 2028), Selenopeltis macrophtalma macrophtalma (KLOUCEK) (Jbel Tachilla: ex "Ceratocephala buchi" sensu Termier y Termier, 1950c, lám. 194, Fig. 1 -original de Bigot y Dubois 1931-; fide Hammann et al., 1986), Dionide sp. (1320), Lichida indet. (1320).

- Ostrácodos: "Brephocharieis aff. complicata (SALTER)" (1320, 1363: citado como Tetradella aff. compli-cata, det. N. Grékoff).

- Graptolitos: "Expansograptus cf. hirundo" SALTER $\left(68^{*}\right.$, 521*?, 598*?, 665*?), Expansograptus ? sp. $\left(441^{*}\right)$, Corymbograptus? retroflexus (PERNER) $\left(440^{*}, 441^{*}, 442^{*}=\right.$ $447^{*}, 487^{*}=493^{*}-494^{*}, 488^{*} ?, 495^{*}-497^{*}=505^{*}, 521^{*}$, $1573^{\star}$ ?), Didymograptus (Jenkin-sograptus) spinulosus (PERNER) (1050*), D. (Didy-mograptus) ex gr. artus ELLES and WOOD y/o D.(Jenkinsograptus) ex gr. spinulosus (PERNER) $\left(729^{*}, 733^{*}, 852,1065^{*}\right.$ y 1890 -citados como "D. g r . inden-tus" o " $D$. cf. bifidus"-; " $D$. g $\mathrm{r}$. indentus" de la loc. $491^{*}$ pudiera ser también Aulograptus? sp.), Tetragraptus sp.(598*?, 665*?), Didymograptus s.l. spp. (1233, 1325, 1570*, $\left.1571, \quad 1573^{*}\right), \quad$ Haddingograptus? sp. $\left(495^{*}=\right.$ "Pseudoclimacograptus aff. scharenbergi LAPW." in Destombes et al., 1985 y publicaciones previas), Hustedograptus? sp. (1347) [= "Glyptograptus cf. teretiuscu-lus (HISINGER)" in Destombes et al., 1985], "Dictyo-nema amplum RUEDEMANN" (Imini**: Termier y Termier, 1947, 1950), otros graptolitos dendroideos $\left(100^{*}, 734^{\star *}\right)$, graptolitos indet. $\left(437,1050^{*}, 1213\right)$.

$\bullet$

Braquiópodos: Euorthisina minor HAVLÍC ${ }^{\curlyvee}$ EK (1050*, 1320), restos indeterminados $(1218,1230,1236,1363,1873)$, linguliformes (1236, 1575, 1793, 1890 -obólido de gran talla-).

- Equinodermos: Calix segaudi (TERMIER y TER-MIER) $\left(499^{* *}, 1872\right)$, restos indet. (1874).

- Bivalvos: Redonia deshayesi ROUAULT $\left(1050^{*}, 1065^{\star}\right.$, 1320,1363 ), Praeleda cf. sharpei (BABIN y GUTIÉRREZMARCO) (1320), cf. Ctenodonta esco-surae (SHARPE) (1320), restos indet. $\left(1247,1347,1363,1528,1572^{\star}, 1575\right.$, $\left.1793,1869^{* *}, 1890,2028\right)$

- Gasterópodos: Tropidodiscus pusillus (BARRANDE in PERNER) (1050*, 1236*, 1247, 1320); Ptychonema marocanum HORNÝ (1247, 1320+), Lesueurilla prima (BARRANDE in PERNER) (1247, 1320), Sinuites sowerbyi (BARRANDE in PERNER) (1320), Selesinui-tes perneri HORNÝ (1320), gasterópodos indet. $\left(729^{*}, 1213\right.$, $1218,1230,1236,1247,1363,1528,1572^{*}$,

2028).

- Tergomiidos (ex "monoplacóforos"): Cyrtodiscus niti-dus (BARRANDE in PERNER) (1320), Tachillanella tafilaltensis HORNÝ (1320+), Thoralispira? sp.(563*).

- Hyolitha: Pauxillites pauxillus meridionalis MAREK $\left(1050^{*}+\right)$, Pauxillites sp. $\left(1236^{*}\right)$, Elegantilites hejaren-sis MAREK (1320 +, 1528?), Elegantilites aff. beni-gnensis (NOVÁK) (1363), Gompholites cf. cinctus (BARRANDE) (1230), Gompholites sp. (1320), hiolíti-dos indet. $\left(52^{*}, 1213,1218,1572^{*}\right)$.

- Otros: ortotécidos indet. (563*), nautiloideos ortoconos (1236, $1320,1575)$, conuláridos $\left(52^{*}, 1793\right)$, Chondri- 
tes isp., Teichichnus isp., Palaeophycus isp. (icnofósiles frecuentes en diversas localidades), pistas bilobuladas (1873) y microfósiles de pared orgánica (quitinozoos y acritarcos: Deunff, 1977; ElaouadDebbaj, 1984, 1987; esencialmente de las localidades $436^{*}, 438^{*}, 440^{*}, 489^{*}, 497^{\star}$ y $2405^{\star}$ ). El yacimiento $440^{*}$ (base de la Formación Tachilla: Arenigiense superior) constituye la localidad y estratotipo de los acritarcos Veryhachium angustum, Evittia flosmaris, Peteinosphaeridium pen-natum, Baltisphaeridium Ilanvirnensis y Cymatiogalea zagoriensis, descritos por Deunff, 1977).

\subsection{Tránsito entre las Formaciones Tachilla y Taddrist}

Destombes (in Destombes et al., 1985: p. 193) describió el límite entre los grupos Feijas Externas y Primer Bani (techo de la Formación Tachilla/base de la Formación Taddrist) como muy gradual, por incremento progresivo en las interca-laciones arenosas que van a predominar de un modo caracte-rístico en la segunda de estas unidades. El reconocimiento del límite propiamente dicho se ve favorecido localmente por la existencia de un "thin lumachellic limestone marker" contiguo a otro importante horizonte de referencia, el lla-mado "Nivel Ferruginoso de Tourza", que a su vez se apoya discordante sobre la Formación Tachilla en amplias regiones del Anti-Atlas (Destombes, 1983a, c, 1987; Destombes et al., 1985). La existencia de esta leve discordancia angular per-mite asociar con seguridad dicho horizonte ferruginoso al ciclo sedimentario representado por el Grupo Primer Bani, cuya base adquiere localmente un carácter "transgresivo" y encierra una pequeña laguna estratigráfica dentro del Oretaniense (por la erosión previa del techo de la Formación Tachilla recubierto en discordancia: Destombes, 1987).

Con todo, la adscripción litoestratigráfica del "nivel del-gado de caliza lumaquélica" (en realidad más de uno en varias secciones) resulta a menudo problemática, así como la de importantes yacimientos paleontológicos asociados a lu-maquelas calcáreas en el tránsito entre las formaciones Tachilla/Taddrist y Taddrist/BouZeroual, donde se sitúan las localidades-tipo de varios taxones nuevos definidos en el Anti-Atlas. Algunas intercalaciones calcáreas corresponden claramente a los últimos $35 \mathrm{~m}$ de la Formación Tachilla, con los yacimientos 714, 1527, 1529 y 1795, el último cierta-mente discordante bajo el Nivel Ferruginoso de Tourza, per-teneciente al Primer Bani. Además de ello, la adscripción d e éstas y otras localidades semejantes (273, 1598, 1906) per-manecía hasta hace poco controvertida: muchas publicacio-nes las sitúan en la Formación Taddrist, alguna en la Forma-ción Bou-Zeroual, o incluso en un tramo de transición diferenciado informalmente como "formación Kissane" (ver Havlíc`ek, 1971), integrándolas en todo caso en el Grupo Primer Bani referido tradicionalmente al "Llandeilo". Parte de estos puntos y algunos otros horizontes calcáreos luma-quélicos, atribuídos en un principio a la Formación Taddrist por su semejanza con los citados, fueron reasignados luego por Destombes (1983a, 1985, 1988 y presente trabajo) tanto a la Formación Bou-Zeroual (yacimientos 19, 20, 273, 277, 1598, 1867 -p.p.-), como a la Formación Guezzart (idem. 154 y 1826).

No obstante, la asociación paleontológica de los niveles de tránsito entre las formaciones Tachilla y Taddrist, en su mayor parte asignables con seguridad a la parte más alta de la Formación Tachilla (localidades 714, 1527, 1529, 1795, 1906), es bastante homogén e a y reúne los siguientes taxones:

- Trilobites: Morgatia? rochi (DESTOMBES) (1527),

"Zeliszkella" sp. (1795), Neseuretus sp. (1906), Colpo-coryphe sp. (1795, 1869), Bathycheilus sp. (1527), Eo-homalonotus sp. (1527), Asaphidae (1527, 1870, 1906), Cheiruridae (1870), Phacopina (1869, 1870), restos in-det. (714).

- Graptolitos: D. (Didymograptus) murchisoni (BECK in MURCHISON) (734).

- Braquiópodos: "Orthambonites" fraternus HAVLíC" EK (1795, 1906), Euorthisina minor HAVLÍC EK (1527), restos indet. (1527, 1529), linguliformes (1527, 1529,

1869).

- Equinodermos: Calix segaudi (TERMIER y TERMIER) $(1795,1869)$ (más yacimientos 499 y 1872).

- Moluscos: Redonia sp. (714), bivalvos indet. (1869, 1870).

- Otros: conuláridos (1527), restos de briozoos y ostrácodos (1527), graptolitos indet. (1529, 1870), Trichophy-cus isp. (Jbel Adoumaz).

A esta lista deben unirse también otros taxones, de distribución m ás amplia, mencionados para algunas localidades de la parte superior de la Fm. Tachilla, en la relación que figura en el apartado precedente (yacimientos 168, 499, 734 y 1869).

\subsection{Formación Taddrist}

- Trilobites: Morgatia? rochi (DESTOMBES) $\left(1600^{*}+\right)$, Zeliszkella (Mytocephala) sp. (1600*), Colpocoryphe sp. (1600*), Eccoptochile sp. (?), "Ogygiocaris" sp. (602), Asaphidae (214, 1997).

- Graptolitos: D. (Didymograptus) murchisoni (BECK in MURCHISON) (1193), Didymograptus spp. (Jbel Taddrist* $^{*}$ 736, 737, 1193).

- Equinodermos: Calix segaudi (TERMIER y TERMIER) $\left(1699^{* *}, 1868^{* *}\right)$, Sphaeronites? sp. B CHAUVEL $\left(1699^{* *}\right)$.

- Moluscos: Cardiolaria beirensis (SHARPE) $\left(221^{*}, \mathrm{PF}\right.$ $\left.691^{*}\right)$, Modiolopsis sp. (PF 691*), cf. Hemiprionodonta lusitanica (SHARPE) (602), grandes bivalvos (1868?, 1997), nautiloideos ortoconos (1997).

- Conodontos: Drepanoistodus? sp., Paraprioniodus? sp., "Scandodus" sp., aff. Walliserodus nakholmensis (HAMAR) (El Bourkhissi y Sarmiento, 1997).

- Otros: hyolítidos indet. $\left(1868^{\star *}\right)$, linguliformes (Zagora), Skolithos isp., Daedalus isp. 


\subsection{Formación Bou-Zeroual}

- Trilobites: Crozonaspis chouberti DESTOMBES $\left(20^{* *}+\right)$, Morgatia zguidensis (DESTOMBES) $\left(20^{* *}+\right.$, $\left.277^{* *}\right)$, "Zeliszkella" sp. $\left(561^{*}, 277^{* *}, 1912^{* *}\right)$, Neseu-retus sp. $\left(19^{* *}, 20^{* *}, 273,276^{* *}, 277^{* *}, 561^{*}, 1886^{* *}, 1910^{* *}\right.$, $\left.1911^{* *}, 1912^{* *}, 1925^{* *}\right)$, Colpocoryphe sp. $\left(20^{* *}, 561^{*}\right)$, Bathycheilus sp. $\left(273\right.$ ?, $\left.1700^{*}\right)$, Plaesia-comia sp. $\left(20^{* *}\right)$, Eohomalonotus sp. $\left(273,1881^{* *}, 1886^{* *}\right)$, "Eccoptochile cf. mariana" (VERNEUIL y BARRANDE) (1781), "Ogygiocaris"? sp. $\left(276^{\star *}\right)$, Asaphidae $\left(561^{*}, 1886^{\star *}\right)$, Phacopina indet. $\left(1867,1886^{\star *}, 1911^{\star *}\right)$.

- Ostrácodos: "Quadrijugator permarginatus?" (FOERSTE) (citado como "?Bollia ?permarginata") (273), "Dilobella" sp. (273), cf. "Sigmoopsis platyceras (ÖPIK)" $\left(20^{* *}\right)$, cf. "S. schmidti (BONNEMA)" $\left(20^{* *}\right)$, restos indet. $\left(20^{* *}\right)$.

- Graptolitos: Didymograptus (D.) murchisoni (BECK in MURCHISON) (482, 561).

- Braquiópodos: "Orthambonites" fraternus HAVLÍ “CEK $\left(19^{* *}, 20^{* *}, 1598+\right)$, Atlantida amplexomya HA-VLÍ CEK $\left(20^{\star *}+\right)$, restos indet. $\left(273,1886^{* *}, 1995\right)$.

- Equinodermos: Aristocystites bohemicus bohemicus BARRANDE (19**, 1598), Phlyctocystis regularis (TERMIER y TERMIER) $\left(19^{* *}, 20^{\star *}, 1598,1599,1781\right)$, $P$. gigas (TERMIER y TERMIER) (1781), P. granulata CHAUVEL (1781), Phlyctocystis sp. (1867), Calix sedgwicki ROUAULT (561), Calix segaudi (TER-MIER y TERMIER) $\left(20^{* *}, 1599,1700^{*}\right)$, Diploporita indet. (1598).

- Bivalvos: Redonia sp. (273), Coxiconchia sp. (561*), bivalvos indet. $\left(1867,1912^{* *}, 1925^{\star *}, 1995\right)$.

- Tergomiidos (ex "monoplacóforos"): Quasisinuites rapax HORNÝ (20**?, 273+).

- Hyolitha: Elegantilites ? sp. $\left(20^{* \star}\right)$, Gompholites sp. (273), restos indet. $\left(1886^{\star \star}\right)$.

- Otros: conuláridos (273), nautiloideos (273), quitinozoos (Destombes et al., 1985; Elaouad-Debbaj, 1987).

\subsection{Formación Guezzart}

- Trilobites: Iberocoryphe serrata (TROMELIN) $\left(1896^{\star *}\right)$, Eohomalonotus cf. vicaryi (SALTER) (222), Eohomalonotus sp. (1909), Neseuretus sp. (1909), Colpocoryphe sp. $\left(51^{*}, 241^{*}\right)$, Placoparia (Coplacoparia) sp. $\left(1764^{* *}, 1826^{* *}\right)$, Selenopeltis sp. $\left(1826^{* *}\right)$, Ec-tillaenus sp. $\left(568^{* *}, 621^{* *}, 1826^{\star *}\right)$, Asaphidae $\left(1764^{* *}\right)$, Phacopina indet. $\left(1764^{* *}, 1876\right)$.

- Ostrácodos: Reuentalina sp. nov. aff. queneaui VANNIER, y otras formas indet. $\left(1764^{* *}\right)$.

- Braquiópodos: Tissintia convergens HAVLÍ “CEK (15**, 1576, 1591+, 1876, 1896** , 1924, 1996, 2011).

- Equinodermos: Calix segaudi (TERMIER y TERMIER) $\left(51^{*}, 267^{*}\right), \quad$ C. termieri CHAUVEL (39+), C. sedgwicki ROUAULT $\left(16^{* *}, 593^{* *}\right)$, Phlyctocystis gra-nulata CHAUVEL $\left(51^{*}, 154,593^{\star *}, 1764^{\star *}, 1765\right.$,
1772?, 1826**), $P$. gigas (TERMIER y TERMIER)(51*, $\left.154^{* *}, 1764^{* *}, 1765\right), P$. regularis (TERMIER y TERMIER) $\left(1764^{* *}\right)$, Isidalocystis furca CHAUVEL $\left(1826^{* *}+\right)$, Sphaeronites sp. $\left(154^{* *}\right)$, Diploporita indet.(627: ex "Sinocystis?" sp. CHAUVEL 1966), "Echinos-phaerites belgicus" JAEKEL $\left(593^{* *}\right)$, Cornuta indet.(gen. A VI in Chauvel, 1971) (1826**). Destombes et al.(1985: p. 195) añaden también Calix rouaulti CHAU-VEL, sin indicación precisa de yacimiento. Si éste cor-respondiera a la localidad del Oued Massa (Jbel Ta-chilla), única de incuestionable presencia de la especie en Marruecos (Chauvel, 1966), entonces la Fm. Guez-zart representaría también el estratotipo de las especies $P$. granulata, $P$. gigas y $C$. segaudi, descritas con material del punto mencionado.

- Moluscos: Cardiolaria beirensis (SHARPE) (2011), bivalvos indet. $\left(241^{*}, 1896^{* *}\right)$, gasterópodos indet. (1896**, 2011).

- Hyolitha: Gompholites sp. B MAREK (950), restos indet. (1876).

- Otros: quitinozoos (Elaouad-Debbaj, 1987, Jbel Zagora), icnofósiles ramificados ( $\mathrm{pp}=$ "pseudo-Callograptus" de Termier y Termier: Adrar n'Tasse-fat ${ }^{* *}$ ), Daedalus isp. y Skolithos isp. (Jbel Taouarda).

\subsection{Formación Ouine-Inirne}

- Trilobites: Phacopidina neltneri (DESTOMBES) $\left(156^{* *}, 582^{* *}, 878^{* *}+\right)$, Zeliszkella sp. $\left(1825^{* *}\right), \mathrm{Ne}-$ seuretus sp. $\left(1934^{\star *}\right)$, Eohomalonotus sp. $\left(156^{\star *}, 534\right.$, $\left.581,878^{* *}, 1897,1939\right)$, Placoparia sp. $\left(1825^{\star *}\right)$, Eccoptochile? sp. $\left(156^{* *}\right)$, Selenopeltis sp. $\left(878^{* *}\right.$, $\left.1825^{\star *}\right)$, Ectillaenus sp. $\left(1825^{\star *}\right)$, Asaphidae (156**, $\left.878^{* *}, 1934^{* *}, 1935^{* *}\right)$, Phacopina indet. (1698).

- Equinodermos: Calix cornuta CHAUVEL $\left(1697^{* *}+\right.$, $\left.1763^{* *}\right)$, Phlyctocystis regularis (TERMIER y TER-MIER) $\left(1697^{* *}\right)$, Oretanocalix sp. $\left(1697^{\star *} ; \mathrm{pp}=\right.$ Calix ?cornuta CHAUVEL sensu Chauvel, 1978, Fig. $4 \mathrm{f}$ en el texto: fide Gutiérrez-Marco, 2000), Sphaeronitida indet (1X in Chauvel, 1978) $\left(1763^{* *}\right)$, Rhombifera indet. (1698), Aspidocarpus discoidalis (CRIPPS) $\left(1698^{* *}+\right)$ (ex Chauvelia discoidalis, fide Lefebvre, 2000; = Mytrocystites sp. 2 de Chauvel, 1971; = "Mo-roccan Chinianocarpos" de Jefferies y Lewis, 1978; = Aspidocarpus cf. bohemicus?, fide Ubaghs, 1979), Eumitrocystella savilli BEISSWENGER $\left(1698^{* *}+\right) \quad(=$ ? "Mitrocystella barrandei JAEKEL" de Chauvel, 1971) y Anatifopsis sp. (1698**).

\footnotetext{
- Braquiópodos: Paterorthis paterina HAVLÍ CEK (1939+), restos indet. (534).
}

- Moluscos: Ribeiria pholadiformis SHARPE $\left(1825^{\star \star}\right)$, Cyrtodontula ? sp. (605), Cyrtodontida indet. (1938), bivalvos indet. $\left(878^{* *}, 1933^{* *}\right)$, gasterópodos indet. $\left(1825^{* *}\right)$, nautiloideos ortoconos $\left(878^{* *}, 1825^{* *}\right)$.

- Otros: conuláridos $\left(582^{* *}, 1933^{* *}\right)$, braquiópodos $\left(582^{* *}\right)$, acritarcos $\left(2169^{* *}, 2169 \mathrm{bis}^{* *}, 2340^{* *}\right.$ : 
Elaouad-Debbaj, 1987), quitinozoos (Elaouad-Debbaj, 1987, Jbel Zagora), Skolithos isp., Daedalus isp. (O de Akka).

\subsection{Formación Izegguirene}

- Trilobites: Crozonaspis primula (DESTOMBES) (194, 1645 + , 1898), Crozonaspis sp. $\left(1644^{*}, 1695^{*}, 1908^{*}\right)$, "Kloucekia" sp. $\left(1602^{\star *}, 1908^{\star}\right)$, Morgatia? sp. $\left(629^{\star}, 755\right)$, Degamella princeps princeps (BARRANDE)(755), Kerfornella sp. 2 HENRY y DESTOMBES $\left(1645^{\star *}\right)$, Plaesiacomia sp. $\left(1644^{*}\right)$, Eohomalonotus cf. brongniarti (DESLONGCHAMPS) y E. cf. vicaryi (SALTER) (559, 1644 ?, 1648** $\left.1908^{*}\right)$, Eohomalono-tus sp. $\left(1898,1908^{\star}\right)$, Iberocoryphe cf. verneuili HAM-MANN (535), Neseuretus sp. (535), Placoparia sp.(633*, 755, 1797), "Eccoptochile aff. clavigera BEY-RICH" (1696**), Marrolithus cf. bureaui (OEHLERT)(194, 196, 615, $\left.1695^{*}, 1782^{* *}\right)$, Trinucleidae indet. $\left(1908^{*}\right)$, Selenopeltis sp. (755), Asaphidae indet. $\left(755,1696^{\star *}, 1908^{\star}\right)$, Eoharpes sp. (1696**, 2479**).

- Graptolitos: Dendrograptus sp. (755). Las citas de "Callograptus aff. salteri Hall" realizadas por Choubert (1952) corresponden, en realidad, a un icnofósil peculiar (Destombes et al., 1985). Éste forma acumulaciones en las areniscas de la parte media y alta de la Fm. Izegguirene en el Jbel Bani, al oeste de Foum Zguit (Destombes, 1988), en horizontes atribuídos en trabajos previos a la Fm. Ouine-Inirne.

- Ostrácodos: "Piretopsis (Cerninella) bohemica (BARRANDE)" (citado como "Tallinopsis? bohemica" por Destombes et al., 1985), “Ulrichia?” o "Bollia?" (1645), ostrácodos indet. $\left(1645,1695^{*}, 1908^{*}\right)$.

- Equinodermos: Phlyctocystis regularis (TERMIER y TERMIER) $\left(967^{* *}\right)$, Calix aff. rouaulti CHAUVEL (1797), Calix sp. (631?, 755), Aristocystites? sp. (1797), Destombesia? sp. (1601**), "cf. Isidalocystis? sp." (1696**, $\left.1824^{\star *}\right)$, "Mitrocystites sp. 1" CHAUVEL $\left(1824^{\star *}\right)$, cf. Scotiaecystis sp. $\left(2479^{* *}\right)$, Anatifopsis sp. $\left(755,2479^{* *}\right)$, aff. Lyricocarpus sp. (gen. A VIII in Chauvel, 1971, fide Ubaghs, 1994 y Lefebvre y Viz-caïno, 1999) (755), Ophiuroidea indet. $\left(2479^{* *}\right)$, Aste-rozoa indet. (755).

- Braquiópodos: Tafilaltia sp. A HAVLí こCEK (1602**), Tafilaltia s p . B H A V L I “CEK (609**), "Mimella" sp. B HAVLÍ “CEK (1602**), linguliformes (755).

- Moluscos: Cardiolaria sp. (1908*), bivalvos indet.(s/ $\left.\mathrm{n}^{* *}, 194,535,1898\right)$, gasterópodos indet. (194, 755), hiolítidos indet. $\left(755,1908^{*}\right)$.

- Conodontos: Distomodus? cf. tamarae LINDSTRÖM, Racheboeuf y Henry, Plectodina sp., Coelocerodontus?sp., Phragmodus? sp. (El Bourkhissi y Sarmiento, 1997).

- Otros: conuláridos $\left(629^{*}, 1695^{\star}\right)$, Skolithos isp., Dae-dalus isp., quitinozoos (2433**: Biozona de Lagenochi-tina ponceti fide Elaouad-Debbaj, 1987).

\section{Unidades bioestratigráficas}

Destombes (in Destombes et al., 1985: p. 196), propuso diversas biozonas (cuatro de trilobites, dos de braquiópodos y una de equinodermos) para el conjunto estratigráfico analizado. Sin embargo, estas unidades presentan dificultades en cuanto a su reconocimiento práctico, por varias razones. En primer lugar, los taxones nominales de las biozonas de trilobites están representados en un número muy reducido de localidades, variando por el momento entre una (Crozonas-pis chouberti, Degamella princeps) y tres (Morgatia zgui-densis, Eohomalonotus cf. vicaryi, Phacopidina neltneri), para las formas citadas entre paréntesis. En segundo lugar, se constata que la asignación a formaciones concretas de diver-sos estratotipos de biozonas, así como su secuencia dentro del Grupo Primer Bani, ha variado notablemente tras la presente revisión bioestratigráfica (Fig. 3), atribuyéndose h o y e $\mathrm{n} d$ ía a la Formación Bou-Zeroual sendas biozonas de trilobites y braquiópodos (Biozona de Crozonaspis choy-berti + Morgatia zguidensis y Biozona de "Orthambonltes" fralternus + Atlantida amplexomya, respectivamente), que antes eran asignadas a la Formación Taddrist. En tercer lugar, la Biozona de concurrencia de equinodermos (Calix sed-gwicki + Phlyctocystis granulata + Phlyctocystis gigas) estaría restringida virtualmente a las formaciones Guezzart y Bou-Zeroual, teniendo en cuenta además que hasta ahora sus tres especies nominales no coexisten en ningún yacimiento conocido.

Por todas las consideraciones expuestas, se deduce la escasa entidad del esquema bioestratigráfico previo, cuya posibilidad de aplicación en correlaciones a larga distancia resulta igualmente problemática: la mayoría de sus taxones nominales, o bien tienen un carácter endémico, o son excesivamente raros, o bien aparecen ligados a facies sedimentarias concretas, con amplio diacronismo potencial.

Únicamente la Biozona de Tissintia convergens parece restringirse a la Formación Guezzart, tal y como había propuesto Destombes (in Destombes et al., 1985), y podría ser de cierta utilidad para la correlación entre los materiales del Dobrotiviense inferior del Anti-Atlas con respecto a los del suroeste europeo.

Sin embargo y ateniéndonos al grado de conocimiento actual, no creemos factible establecer, por el momento y con carácter general, divisiones bioestratigráficas formales para el conjunto de la sucesión del Ordovícico Medio en el Anti-Atlas marroquí.

\section{Correlación estratigráfica con Ibero-Armórica}

Desde el punto de vista del desarrollo sedimentario, los materiales del Ordovícico Medio del Anti-Atlas comparten, en sentido amplio, algunos caracteres comunes con las "Ca-pas con Tristani" del suroeste de Europa, como son la diferenciación de una primera unidad de pizarras fosilíferas (Formación Tachilla: "Llanvirn" auct.), sucedida por un conjunto 
con predominio arenoso (Grupo Primer Bani: "Llandeilo" auct.). Dentro de este último se individualizan unidades cuar-cíticas comparables con otras semejantes del Dobrotiviense iberoarmoricano (Cuarcitas Inferiores y de Los Rasos, Cuar-cita Botella, Grès de May Inferior, Formaciones Monte da Sombadeira y Cabril, etc.), que registran biofacies compara-bles de trilobites (Henry y Destombes, 1991), e incluso tienden a evolucionar hacia ambientes más profundos a final del Dobrotiviense (niveles con Marrolithus bureaui o M. e x gr. bureaui en facies "Ouljet-bou-Khemis", representados también en el Alto Atlas y en el Macizo Hercínico Central marroquí: Termier, 1936, Cornée y Destombes, 1991).

A un mayor detalle, el desarrollo litoestratigráfico de los dos conjuntos predominantes (pizarroso inferior y arenoso superior) presenta, en el Dominio hercínico presahariano, grandes diferencias con relación a las "Capas con Tristani" sureuropeas. La más importante es que el carácter generali-zado de la sedimentación arenosa comienza bastante antes en el norte de África, hacia finales del Oretaniense inferior, en tanto que las "Capas con Tristani" resultan ser esencialmente pizarrosas durante todo el Oretaniense. Hamoumi (2001) adscribe al Grupo Primer Bani un carácter deltaico, mientras que en el suroeste de Europa, los depósitos arenosos del Ordovícico Medio poseen un carácter tempestítico (Bren-chley et al., 1986). Tales depósitos sólo empiezan a generali-zarse en Ibero-Armórica a partir de la parte media del Dobro-tiviense inferior, alcanzando gran extensión e $\mathrm{n}$ e l Dobrotiviense superior (San José et al., 1992). La única excepción a esta regla se da en áreas concretas del Macizo Armoricano, donde los materiales dobrotivienses finalizan con un nuevo tramo pizarroso (Subbiozona de Marrolithus bureaui: Henry, 1980, con referencias previas). Otras dife-rencias sensibles en el desarrollo sedimentario del Ordoví-cico Medio entre el sur de Europa y el norte de África, derivan de la existencia de condiciones físicas y ambientales distintas en el seno de ambas partes de la plataforma perigondwánica, que tuvo un mayor gradiente relativo $\mathrm{y}$ aguas más $f r$ ías en el actual Dominio del Anti-Atlas. Ello redunda en la existencia de medios más abiertos y/o profundos en este sector norteafricano durante el depósito de las unidades pi-zarrosas, lo cual se manifiesta por un mayor influjo de las faunas "bohémicas" allí representadas, en detrimento de las "biofacies con Neseuretus" típicas, comunes en las platafor-mas más someras y energéticas del área ibero-armoricana. En cierto sentido, la Formación Tachilla parece heredar, a grandes rasgos, el ambiente sedimentario general descrito para la Formación Fezouata Superior por Vidal (1996, 1998a), donde la "biofacies con Colpocoryphe" y otras bio-facies más profundas o distales, predominan notablemente sobre la "biofacies con Neseuretus". Esta última se restringe a dos pequeños tramos del tercio terminal de la Formación Fezouata Superior y a I a F ormación Zini, en tanto que resta por acreditar su caracterización en la Formación Tachilla, donde los raros hallazgos de Neseuretus corresponden a restos resedimentados.

\section{Aspectos cronoestratigráficos y biocronológicos}

\section{El esquema cronoestratigráfico aplicado tradicionalmente}

al Ordovícico Medio del Anti-Atlas, consiste en considerar a la Formación Tachilla como "Llanvirn" y al Grupo Primer Bani como "Llandeilo" (Fig. 4). Thales asignaciones perviven prácticamente inalteradas y siguen reiterándose en publicaciones modernas (Babin y Destombes, 1990; Piqué et al., 1991; Horný, 1997b). La única variación habida en los últi-mos años es la caracterización del límite Arenig-Llanvirn por encima de la base de la Fm. Tachilla (Elaouad-Debbaj, 1984), así como algunas discrepancias acerca de la correlación ge-neral de la sucesión marroquí con respecto a las formaciones del Ordovícico de Bohemia (Fig. 4). En términos de compa-ración con el Ordovícico británico, tas las propuestas pre-vias se refirieron a su ajuste con la escala tradicional de las "series" Llanvirn y Llandeilo, cuya extensión y significado respectivo ha sido revisado una vez más por Fortey et al.(1995) y vuelto a enmendar por Bettley et al. (2001). La nueva "serie Llanvirn" (redefinida), englobando los pisos regionales Abereiddiense y Llandeiliense, perdió la pugna para constituirse como referente mundial del Ordovícico en favor del Darriwiliense, dado que tenía importantes proble-mas de correlación relativos a su límite inferior, así como escasas posibilidades de correlación de sus pisos integrantes fuera del contexto del noroeste europeo (ver por ejemplo Fortey et al., 1990, 1995; Maletz, 1992, 1997; Berry, 1995; Chen y Bergström, 1995; Finney, 1996; Mitchell et al., 1997; Webby, 1998). Su aplicabilidad en las regiones nord-gond-wanienses había sido puesta en duda, entre otros, por Ha-vlíček y Fatká (1992) y Gutiérrez-Marco et al. (1995, 2002). Estos últimos autores proponen adoptar una escala regional mediterránea más completa, ante la imposibilidad de fijar índices comunes de correlación con el Darriwilliense o con la escala británica, al hecho de disponer de subdivisiones más finas a escala regional, y a s u homologación operativa con múltiples escalas regionales (asiáticas, norteamericanas, no-reuropeas, australianas), cuya vigencia goza de un amplio consenso local. En el presente trabajo extendemos por vez primera la utilización de los pisos regionales Oretaniense y Dobrotiviense a la sucesión del Anti-Atlas marroquí, debido a sus buenas posibilidades de correlación con Bohemia y con el suroeste de Europa, áreas con las que se comparten impor-tantes vínculos biogeográficos y paleogeográficos. No obs-tante, otros autores prefieren modernizar la asignación tradi-cional con arreglo a los nuevos términos regionales británicos, considerando esencialmente a la Formación T a - chilla como Abereiddiense y al Grupo Primer Bani como Llandeiliense (Mélou et al., 1999: p. 835; Hamoumi, 2001).

Con la propuesta hecha en este trabajo de adoptar la escala regional mediterránea como base de correlación para el Ordovícico Medio del Anti-Atlas, se obvian también los principales problemas de correlación de los que adolece la escala británica, en su pretensión fallida de erigir al Llanvirn como patrón internacional del Sistema Ordovícico. La problemática esencial se centra en los siguientes aspectos: 
- En primer lugar, la aparición d e Didymograptus (Didymograptus) y d e D. (Jenkinsograptus) en Gran Bretaña no constituye un criterio homologable para correlacio-nar la base del Llanvirn a nivel global, dado que en Escandinavia y Norteamérica, dichos taxones aparecen hacia la base de la Biozona de Holmograptus lentus, que resulta ser más antigua que los horizontes británicos equivalentes (Maletz y Mitchell, 1995; Maletz, 1997: ambos con referencias previas). En opinión de Maletz (1997), la base del Llanvirn redefinido (Fortey et al., 1995) se correlaciona con la base de la Biozona de Nicholsonograptus fasciculatus de otras sucesiones mundiales (Maletz, 1997). En consecuencia, el criterio británico para fijar el estratotipo de la base del Abereid-diense, está sujeto a diacronismos que lo hacen inviable a efectos de correlación formal, por lo cual la utilización regional del piso Oretaniense en el norte de Gondwana obviaría estos problemas.

- En segundo lugar, la Biozona de Didymograptus murchisoni en el Abereiddiense británico parece representar tan sólo la parte terminal del Abereiddiense superior de otras sucesiones mundiales correlacionables, con probada ausencia de registro de los equivalentes de la Biozona de Pterograptus elegans infrayacente (caracterizada en Escandinavia, Norteamérica o China: ver Maletz, 1997), que por el contrario sí encuentra correla-ción en el Oretaniense mediterráneo (niveles con Ptero-graptus de los macizos Armoricano y Hespérico: cf. GutiérrezMarco, 1986; Gutiérrez-Marco et al., 1999a).

- En tercer y último lugar, el Llandeiliense (= Llanvirn "superior") británico también presenta dificultades de correlación a escala internacional y mediterránea, respectivamente. Las primeras derivan del reconocimiento de la Biozona de Hustedograptus teretiusculus, como equivalente al rango total de este piso. Su especie nomi-nal [Hustedograptus teretiusculus (HISINGER) sensu JAANUSSON] arrastra muchos problemas taxonómi-cos, y el rango vertical de la misma excede con mucho al Llandeiliense, abarcando en Europa desde la base del Abereiddiense superior hasta el Aureluciense superior, de acuerdo con la propia terminología cronoestratigrá-fica anglo-galesa. A escala mediterránea, la utilización del Llandeiliense resulta inviable, principalmente en ra-zón de que el límite inferior del Caradoc redefinido (la base de la Biozona de Nemagraptus gracilis: Fortey et al., 1995) o el propio graptolito nominal con el que se establece el límite, no puede ser reconocido por las especiales características de la plataforma nord-gondwaniense, cuyas sucesiones son demasiado some-ras para la vida y preservación de graptolitos mesopelá-gicos como $N$. gracilis (HALL). La moderna revisión de la base de la Biozona de $N$. gracilis en el sur de Gran Bretaña (Bettley et al., 2001) suma incluso nuevas incer-tidumbres a su correlación internacional (Bergström e t al., 2000).
El empleo de los pisos regionales Dobrotiviense y Berouniense obvia la imposibilidad de reconocer el límite Llanvirn/ Caradoc (o el límite Ordovícico Medio-Superior) en un amplio sector peri-gondwánico. El horizonte de trán-sito se localiza presumiblemente hacia la parte terminal del Dobrotiviense, según muestran otros argumentos paleontoló-gicos indirectos (Gutiérrez-Marco et al., 1995). El más im-portante de ellos es la confirmación de la presencia, en el Dobrotiviense terminal de la Cordillera Ibérica, de Oepiko-graptus bekkeri (ÖPIK, 1927) (Gutiérrez-Marco et al., 1999b), un graptolito común en el piso Kukruse de la cuenca baltoescandinava (Biozona de Nemagraptus gracilis: Obuty Sennikov, 1987, con referencias previas). Además de este dato, los materiales del Dobrotiviense superior tardío (Sub-biozona de Marrolithus bureaui de trilobites) han permitido caracterizar la Biozona de Lagenochitina ponceti de quitino-zoos, primero atribuida al "Llandeilo tardío" (Paris, 1990, 1996) y más recientemente al Aureluciense británico (Mélou et al., 1999), el cual representaría el Ordovícico Superior basal (Caradoc temprano según Fortey et al., 1995). En el Anti-Atlas, la especie Lagenochitina ponceti fue identificada en la parte superior de la Formación Izegguirene (Elaouad-Debbaj, 1987), y por lo tanto el límite Ordovícico Medio/Ordovícico Superior debemos situarlo dentro del Grupo Pri-mer Bani y no en la base de la Formación Ktaoua Inferior, donde lo habían fijado autores previos (Fig. 4).

De todos modos, la dificultad esencial de correlación entre las escalas regionales británica y bohémica/nordgondwaniense, radica únicamente en el problema de la es-casa percepción de la utilidad de la segunda, por parte de quienes pretenden imponer a ultranza la escala británica como referente de correlación para el Ordovícico en el norte de Gondwana. Cada nuevo trabajo publicado por determinad o s e i n fluyentes autores británicos y franceses, introduce de hecho modificaciones subjetivas al marco de correlación británico-bohémico, sin aportar argumentos que justifiquen tales variaciones, e ignorando completamente la existencia del piso global Darriwiliense. Dos ejemplos recientes de esta práctica son las correlaciones presentadas por Mélou et al.(1999) y Fortey et al. (2000).

Fortey et al. (2000: Fig. 34) equiparan erróneamente el tránsito entre las formaciones Šárka y Dobrotivá de Bohemia (= límite Oretaniense/Dobrotiviense en la escala regional nordgondwaniense) con algún horizonte situado dentro del Llandeiliense británico, aún cuando la extinción de los didymográptidos pendientes (= límite superior del Oretaniense/base del Dobrotiviense) se verifica claramente en el techo de la Formación Šárka (Kraft y Kraft, 1999a, 1999b) y no dentro de la Formación Dobrotivá. El criterio biocronológico inicial para el reconocimiento de la base del Llandeiliense en Gran Bretaña (la aparición de Hustedograptus teretiusculus) coin-cide también con la base de la Formación Dobrotivá en Bohemia, pero no es relevante de cara a la correlación directa de la base del Dobrotiviense, dado que en Baltica y Avalonia el graptolito nominal comienza a ser registrado a partir del Abereiddiense inferior (Maletz, 1997). En consecuencia, la 
nueva modificación propuesta por Fortey et al. (2000) para la correlación entre las divisiones anglo-galesas y las bohémicas nos parece injustificada y no se utiliza en el presente trabajo. Bettley et al. (2001) adoptan la última aparición d e D. (D.) murchisoni como un criterio provisional definitorio para la base de la Biozona de $H$. teretiusculus en el sur de Gran Bretaña. Ello aproximaría la correlación de los límites Oretaniense/Dobrotiviense y Abereiddiense/Llandeiliense, pero implicaría una postrer contradicción con los datos de Fortey et al. (2000), si lo aplicamos a la correlación de la base de la Formación Dobrotivá.

Por último, el trabajo de Mélou et al. (1999) plantea otra hipótesis de correlación con la escala británica, involucrando esta vez una región nord-gondwaniense norteafricana (NE del Sahara argelino), sin hacer tampoco referencia a las divisiones internacionales (el piso Darriwiliense oficial). En dicho estudio se modifican las conclusiones obtenidas para unos mismos sondeos argelinos, planteadas en un trabajo anterior (Oulebsir y Paris, 1995), donde el intervalo de la Biozona de Linochitina pissotensis de quitinozoos era asi-gnado enteramente al "Llandeilo inferior", y el de la Biozona de Lagenochitina ponceti al "Llandeilo superior", siempre en términos de la escala anglo-galesa. El hallazgo de macro-fósiles en ambos intervalos definidos por los quitinozoos lleva ahora a Mélou et al. (1999) a plantear como novedades, para los mismos sondeos, la posibilidad de que "la Biozona de L. pissotensis pueda debutar en el Abereiddiense supe-rior", y la certeza de que la Biozona de $L$. ponceti sea ya Aureluciense (Caradoc basal). Estas dos conclusiones cronoestratigráficas, indemostrables utilizando únicamente los quitinozoos, ya habían sido acreditadas contundentemente con macrofósiles (graptolitos y otros) en referencia a la escala mediterránea. Así, el rango vertical de la parte inferior de la Biozona de $L$. pissotensis se solapa claramente, en el norte de España, con la mitad superior del registro de grap-tolitos "abereiddienses" asignados al Oretaniense superior (Gutiérrez-Marco et al., 1996). Los braquiópodos Cacemia cf. ribeiroi (SHARPE) y Tafilaltia sp. ( $?=$ Heterorthidae indet. de Gutiérrez-Marco et al., 1984), documentados en el NE de Argelia, son formas característicamente pre-dobrotivienses, señaladas en IberoArmórica siempre en el Oretaniense superior (GutiérrezMarco et al., 1984, 1999a). No ha lugar por tanto, a las dudas y reservas expresadas por Mélou et al. (1999) con respecto a la posibilidad de que los horizontes con estos braquiópodos (acompañantes de L. pis-sotensis) tengan ya una edad Abereiddiense, dada la adscrip-ción irrefutable de los mismos al Oretaniense superior, re-suelta con macrofósiles en España.

Un caso diferente son los hallazgos argelinos del braquiópodo Apollonorthis bussacensis (SHARPE), una forma conocida en Ibero-Armórica (Henry et al., 1976; GutiérrezMarco et al., 1984) entre el techo del Dobrotiviense inferior (Sub-biozona de Morgatia hupei de trilobites) y la parte baja del Dobrotiviense superior (base de la Biozona de Placoparia borni de trilobites): es decir, en horizontes situados dentro de la Biozona de L. pissotensis de quitinozoos, de edad claramente pre-Aureluciense. El registro de Apollonorthis bussacensis en Argelia resultaría ser algo más tardío que en Ibero-Armórica, dado que en el norte de Africa la especie concurre con quitinozoos aparentemente más modernos. La asociación d e éstos fue atribuida a la Biozona de $L$. ponceti en ausencia de la especie nominal, determinada para el inter-valo comprendido entre la desaparición de la especie índice de la biozona precedente y el primer registro de la de la siguiente (Oulebsir y Paris, 1995; Mélou et al., 1999). En caso de no haber podido contar con los datos aportados por los quitinozoos, los niveles argelinos con $A$. bussacensis del sondeo Bordj Nili-2 hubiesen sido atribuidos al Dobroti-viense (unidad que incluye el límite Ordovícico Medio/Superior). Pero la precisión inversa apuntada por Mé-lou et al. (1999: p. 830) es radicalmente falsa, en el sentido de que $A$. bussacensis sea una especie aún $m$ ás determinativa dentro del citado intervalo, y que se halle restringida "al Aureluciense del Macizo Armoricano y de la provincia ibé-rica". Esto último implicaría situar a buena parte del Dobro-tiviense en el Ordovícico Superior, siguiendo la interpreta-ción d e M élou et al. (1999), cuando como mucho esta última serie (internacional) debutaría hacia la parte media del Dobrotiviense superior, coincidiendo con las biozonas coetáneas de Marrolithus bureaui (trilobites) y de L. ponceti (quitinozoos). En ellas se ha encontrado un graptolito escan-dinavo de la Biozona de N. gracilis (Gutiérrez-Marco et al., 1995, 1999b) cuya base define el límite Ordovícico Medio/Ordovícico Superior (Webby, 1998; Bergström et al., 2000; IUGS, 2000). Los argumentos basados exclusivamente en quitinozoos tampoco son aplicables de momento a la presente discusión: Mélou et al. (1999) adscriben la Biozona de $L$. ponceti al Aureluciense, basándose principalmente en que la biozona precedente (de L. pissotensis) "no se extiende más allá del techo del Llandeiliense (Paris, inédito)" en Gran Bretaña. Sin embargo, conviene recordar que las caracterís-ticas cronoestratigráficas, bioestratigráficas y litoestratigráfi-cas del Llandeiliense británico distan aún de estar clarifica-das (Bassett y Owens, 1996; Bettley et al., 2001), y también que la contribución del último registro de $L$. pissotensis para deslindar el límite Llandeiliense-Aureluciense s. str., quedaría oscurecida por lo que aparenta ser una nueva biozona regional en ciernes ("O. inflata"), no considerada en el trabajo de Mélou et al. (1999), pero que ya aparece separando las biozonas de $L$. pissotensis y $L$. ponceti en las últimas representaciones de la escala de quitinozoos nordgondwaniense (Paris, 1999: Fig. 2; Paris et al., 1999: Fig. 2).

\subsection{La sucesión oretaniense}

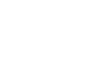

La base de la Formación Tachilla es siempre transgresiva y en su estratotipo (al sur de Agadir) la unidad se apoya paracon-forme sobre las areniscas del Cámbrico Medio (Grupo Taba-nite). En el conjunto del Anti-Atlas, la laguna estratigráfica que marca la base de la formación con respecto a sus unidades infrayacentes (la Formación Fezouata Superior o la Formación Zini, dependiendo de las regiones) tiene una amplitud menor, aunque equivaldría a casi todo el Fenniense (Arenig superior). 
Este piso nunca ha sido identificado paleontológicamente en las unidades previas a la Formación Tachilla (Destombes et al., 1985; Vidal, 1996). El único dato discrepante lo constituíala supuesta presencia de Expansograptus sparsus HOPKIN-SON (un graptolito genuinamente postWhitlandiense) en la localidad 577 (Jebel Signit al sur de Ougnate: Willefert in Destombes, 1985: p. 19), correspondiente a la parte media de la Formación Fezouata Superior. Sin embargo, sobre esta identificación caben serias dudas debido a la posición estra-tigráfica del hallazgo, a los horizontes paleontológicos que lo enmarcan y a I a asociación del graptolito con una especie más antigua como es $E$. cf. pennatulus (HALL).

Por encima de la discordancia de base de la Formación Tachilla, la primera asociación de quitinozoos reconocida en la misma base de la unidad en la región de Zagora (AntiAtlas central), pertenece claramente a la Biozona de Desmo-chitina bulla (ELAOUAD-DEBBAJ, 1984). Ésta representa el Arenigiense terminal en diversas sucesiones de Europa y norte de África (Paris, 1990), por lo que el límite Arenigiense-Oretaniense, establecido en la primera apari-ción d e Didymograptus s.str. en España y en Bohemia (Gutiérrez-Marco et al., 1995; Kraft y Kraft, 1995, 1999a, 1999b), se situaría cerca de la base de la Formación Tachilla (Fig. 4). En cuanto a los graptolitos deflexos y piserialles registrados en los diez primeros metros de esta formación, la única forma identificable con claridad es Corymbograptus ?retroflexus PERNER, citado localmente como "Didymo-graptus v-fractus gigas ROBILLARD", como " $D$. v-fractus wieli LEGRAND", o incluso como " $D$. v-fractus SALTER", en distintas regiones norteafricanas. Las formas "Pseudocli-macograptus aff. scharenbergi LAPWORTH" y "Didymo-graptus cf. hirundo SALTER", reconocidas igualmente en la base de la Formación Tachilla, podrían corresponder, en el primer caso, a una especie de Haddingograptus del Oreta-niense basal, mientras que el segundo debe pertenecer a un robusto didymográptido extensiforme (Expansograptus o Xiphograptus) de la misma edad. De todos modos, la presen-cia del auténtico Expansograptus hirundo SALTER en hori-zontes del Arenigiense superior de la extrema base de la Formación Tachilla, resulta completamente verosímil, tanto en virtud de los datos aportados por los quitinozoos, como considerando que dicha especie ha sido identificada también en horizontes comparables de la base de las "Capas con Tristani”, e n l a r e gión centroibérica (área de Valongo: Couto et al., 1997).

La presencia de didymográptidos deflexos en la parte basal de la Formación Tachilla del Anti-Atlas, así como en otras sucesiones correlacionables del Jebilet occidental, Atlas Medio (Destombes et al., 1985; Willefert y Charrière, 1990) y Sahara argelino (cf. Legrand, 1964), es un hecho bastante singular, que se aproxima también a lo observado en Bohemia (Bouček, 1973; Kraft, 1974, Kraft y Kraft, 1999a, 1999b, 2000), oeste de Francia (localidad de Sionles-Mines: Philippot, 1950 fide Robillard, 1935) y en la región surcen-troibérica española (Gutiérrez-Marco, datos inéditos). El Hassani et al. $(1988,1990)$ consideran que la presencia de estos "Corymbograpti" está directamente asociada con la transgresión atribuible al Llanvirn. En efecto, casi todos los hallazgos africanos y sureuropeos de graptolitos deflexos corresponden a variantes preservacionales de Corymbograp-tus? retroflexus (PERNER), de acuerdo con Bouček (1973) y observaciones propias de uno de los autores (J.C. G.-M.). La aparición de dicha especie en la República Checa y España, precede ligeramente al registro de los primeros didymográp-tidos pendientes (Didymograptus s.str. y Jenkinsograptus), coexistiendo luego con ellos durante buena parte del Oreta-niense inferior tan sólo en Bohemia (Kraft y Kraft, 1993, 1995, 1999a, 1999b, 2000; Gutiérrez-Marco et al., 1995). En las regiones más someras de las plataformas nordgondwanienses, C.? retroflexus se restringe a la base de las sucesiones pizarrosas debido a la progradación $r$ ápida de depósitos semejantes a pizarras negras graptolíticas, durante los primeros momentos de la "transgresión global del Llan-virn" (Fortey, 1984). Estos elementos, junto con ciertos trilo-bites y braquiópodos de hábitos más "pelágicos", desapare-cerían posteriormente al estabilizarse o disiparse el influjo de dicha transgresión (Gutiérrez-Marco y Rábano, 1987). Además de los hallazgos citados, otra forma deflexa de didy-mográptido ("Didymograptus v-fractus") ha sido mencio-nada acompañando a $D$. murchisoni y " $D$. murchisoni gemi-nus" en niveles inusualmente elevados de la Formación Bou-Zeroual (Willefert in Destombes, 1983a: localidad 482 en el Jbel Rhart al NE de Zagora). La muestra completa, ahora revisada, consta de 53 ejemplares de $D$. murchisoni en diver-sos estados de deformación, y entre ellos no existe ningún resto o fragmento auténticamente deflexo. Por último, otras asociaciones graptolíticas de aspecto "arenigiense" (con "Didymograptus patulus, cf. D. hirundo, cf. Tetragraptus fructicosus -sic- y T. serra") han sido citadas recientemente en la parte baja de la Formación Tachilla del Anti-Atlas occidental (Destombes, 2002: p. 22 y Fig. 13). Las dos primeras formas corresponden a graptolitos extensiformes comunes en el Oretaniense inferior, en tanto que la identificación d e Tetragraptus, d e c o n firmarse,

representaría e I r e - gistro más moderno del género en el norte de Gondwana, comparable con hallazgos muy raros del taxón en rocas correlacionables con el Oretaniense de otras partes del mundo (por ejemplo Maletz, 1997, con referencias al área báltica).

La base de la Formación Tachilla intercala también algunos horizontes lumaquélicos de lingúlidos, semejantes en aspecto y condicionantes genéticos a los descritos en torno al límite superior de la Cuarcita Armoricana en múltiples loca-lidades ibero-armoricanas (Emig y Gutiérrez-Marco, 1997). Sin embargo y de un modo comparable a lo que sucede en el suroeste de Europa, los horizontes de lingúlidos más conspi-cuos se localizan en el techo de la Arenisca de Zini, equiva-lente local de la Cuarcita Armoricana en el Anti-Atlas suroc-cidental (Destombes, 1960 y observaciones inéditas).

En la Fig. 4 se presenta una correlación comparativa de las unidades crono- y litoestratigráficas establecida por los dife-rentes autores en la sucesión del Ordovícico Medio del Anti- 


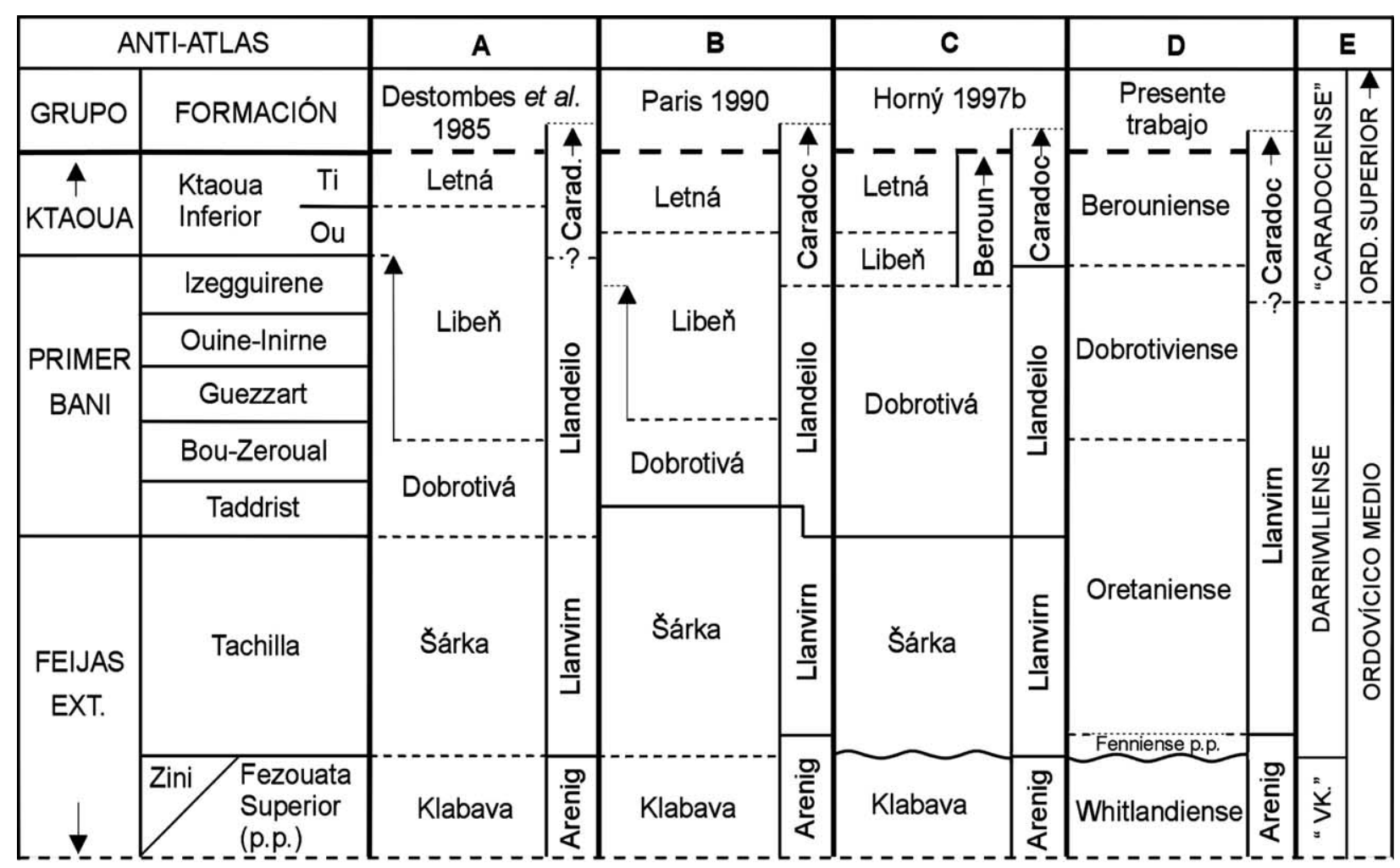

Fig. 4. Correlación entre las unidades del Ordovícico Medio del Anti-Atlas marroquí (izquierda), con respecto a las formaciones bohémicas (AC, izquierda), los pisos de la escala patrón mediterránea (D), las unidades cronoestratigráficas regionales del Ordovícico británico (A-D, derecha), y los pisos globales del Sistema Ordovícico (E). El límite Oretaniense-Dobrotiviense coincidiría aproximadamente con el tránsito Abeiriddiense-Llandeiliense del "Llanvirn" redefinido (Fortey et al., 1995). Las flechas verticales del límite Dobrotivá-Liben” (columnas A, B) indican discrepancias entre la correlación g $r$ áfica y el texto original de los autores respectivos, que en ambos casos admiten la presencia de asociaciones dobrotivienses en la Formación Izegguirene. El límite entre el Oretaniense inferior y superior se sitúa tentativamente en el tercio superior de la Fm. Tachilla, y el límite Dobrotiviense inferior/superior hacia la base de la Fm. Ouine-Inirne. Abreviaturas - (Formación Ktaoua Inferior): Ou., Miembro Ouaouglout; Ti., Mb. Tiouririne Inferior; (Columna E): VK, piso "Volkhoviense" (emend.) de la Serie Ordovícico Medio (el "Caradociense" de la misma columna también presenta enmiendas). Fuentes: A, Destombes (in Destombes et al., 1985: fig. 42); B, Paris (1990: fig. 3, $n^{\circ} 21$ y fig. 2, n 2, respectivamente); C, Horný (1997b: fig. 2); D, elaborada esencialmente con datos inéditos de Destombes (1983-2002); E, s e g ún Webby (1998: fig. 4).

Fig. 4. Correlation chart for Middle Ordovician lithostratigraphic units of the Moroccan Anti-Atlas (left column) with regard to: A to C/left side, the Bohemian Ordovician formations; A to D/right side, the British Ordovician regional scale; D, Mediterranean Ordovician stages (North Gondwanan regional scale); and E, global Stages for the Ordovician (repport in progress). The Oretanian/Dobrotivian boundary can be approximately correlated to the Abereiddian/Llandeilian transition of the "Llanvirn series" (redefined by Fortey et al., 1995). Vertical arrows in columns $A$ and $B$ point discrepances between graphic and written correlations in the original papers, with regard to the boundary between the Dobrotivá and Liben" formations, both admitting the presence of Dobrotivian faunas within the Izegguirene Formation. Abbreviatures: Ou., Ouaouglout Member; Ti., Lower Tiouririne Mb. (Lower Ktaoua Formation); VK, provisional Volkhovian Stage ("stage 2") of the Middle Ordovician Series (column E). Source of data: A, Destombes (in Destombes et al., 1985: fig. 42); B, Paris (1990: data from columns $N^{\circ} 21$ in fig. 3 -left- and $\mathrm{N}^{\circ} 2$ i n fig. 2 -right-, respectively); C, Horný (1997b: fig. 2); D, present work, using unpublished biostratigraphic data from Destombes (1983 to 2002); E, after Webby (1998: fig. 4).

Atlas. La novedad más importante que aporta el presente trabajo, es la extensión del límite Oretaniense/Dobrotiviense a la parte media de la Formación Bou-Zeroual, donde se localizan los últimos representantes del subgénero Didymograptus (Didymograptus), de acuerdo con los datos original e s e i n éditos de Destombes (1983a). En estudios previos y hasta 1997, este límite se hacía equivaler, en la práctica, con el tránsito entre las formaciones Techilla y Taddrist (Fig. 4), que como hemos visto arrastra también una problemática litoestratigráfica particular.

A falta de estudios bioestratigráficos de detalle, el límite entre el Oretaniense inferior y el Oretaniense superior podría situarse tentativamente en el tercio superior de la Formación Tachilla, donde se registran los primeros representantes indu- dables de $D$. (D.) murchisoni. Estos fueron obtenidos en secciones situadas en el Anti-Atlas occidental y central, próximos al techo de la unidad en esta última región (Destombes, 1983a). Paralelamente, en el tercio superior de la Formación Tachilla es donde se registra un relevo apreciable entre los elementos bentónicos, con la aparición de nuevos taxones de equinodermos (Calix segaudi), braquiópodos ("Orthambonites" fraternus) y trilobites (Morgatia? rochi), que van a proseguir su representación en la parte baja del Grupo Primer Bani.

\subsection{La sucesión dobrotiviense}

Los primeros materiales dobrotivienses se identifican, de forma tentativa, en la parte superior de la Formación Bou- 
Zeroual. Al criterio biocronológico de la extinción d e I o s didymográptidos pendientes, podemos sumar la aparición de nuevos taxones de trilobites [Crozonaspis chouberti DES-TOMBES, Morgatia zguidensis (DESTOMBES)] y braquió-podos (Atlantida amplexomya HAVLÍ CEK), que parecen estar restringidos al Dobrotiviense basal africano. A las for-mas citadas se unen más tarde otros braquiópodos (Tissintia convergens y Paterorthis paterina) que podrían ser útiles para la correlación del Dobrotiviense inferior s.l. y de los niveles próximos a la base del Dobrotiviense superior, respectivamente.

Por lo que respecta a la situación del límite Dobrotiviense inferior / Dobrotiviense superior en el seno de la sucesión del Primer Bani, sólo podemos estimarlo de momento como situado por encima del horizonte con Reuentalina sp. nov. aff. queneaui VANNIER, presente en la parte alta de la Formación Guezzart. El límite en sí mismo coincidiría aproximadamente con la base, o bien con algún horizonte aún por determinar, dentro de la Formación Ouine-Inirne suprayacente. Los argumentos planteados por GutiérrezMarco et al. (1997) se fundamentan en las circunstancias estratigráficas de las restantes especies del ostrácodo Reuen-talina, conocido en las Cuarcitas Skalka de la parte inferior de la Formación Dobrotivá (Schallreuter et al., 1996), y dado que $R$. queneaui VANNIER precede la aparición d e $R$. ribei-riana (JONES) en el Dobrotiviense inferior lutítico del Ma-cizo Armoricano (Vannier, 1986).

La identificación plena de asociaciones del Dobrotiviense superior se manifiesta hasta ahora únicamente en la Formación Izegguirene, que alberga diversos horizontes con Marrolithus y Tafilaltia, siendo el primero de estos géneros conocido únicamente en materiales de dicha edad en el suroeste de Europa (cf. Gutiérrez-Marco et al., 1995: Tabla 1). Asimismo, en una localidad aislada de la parte media de la Formación Izegguirene se registra Degamella princeps princeps, un ciclopígido originalmente descrito en la mitad superior de la Formación Dobrotivá de Bohemia (Destombes, 1966: p. 43). También la forma endémica Crozonaspis primula muestra caracteres intermedios con Dalmanitina, u $\mathrm{n}$ género de trilobites característico del Berouniense mediterráneo (Hammann, 1974: p. 65). La forma de ostrácodo más común en los mismos horizontes es Piretopsis (Cerninella) cf. bohemica, una especie de la Formación Viniče (Berouniense), cuyo registro marroquí precede su aparición e n B o-hemia, y que aparece igualmente asociada a Marrolithus aff. bureaui y a Dalmanitina en una formación distinta del Alto-Atlas occidental (Cornée y Destombes, 1991).

En cuanto a la datación del techo del Grupo Primer Bani, un argumento importante proviene del estudio de los quitinozoos. Así, Elaouad-Debbaj (1987: p. 72), determinó la presencia de Lagenochitina ponceti en la parte superior de la Formación Izegguirene; su biozona homónima ha sido atribuída al "Llandeilo tardío" por Paris (1990) y al Dobrotiviense superior por Gutiérrez-Marco et al. (1995). Por otra parte, en la parte más baja de la Formación Inferior de Ktaoua han sido caracterizadas las biozonas sucesivas de Lagenochi- tina deunffı y, sobre todo, de Lagenochitina dalbyensis (Elaouad-Debbaj, 1986). Ello concuerda con la edad Berouniense temprano (Liben־-Letná) asignada a la macrofauna de los mismos niveles (Destombes et al., 1985). Por lo tanto, el tránsito entre los Grupos de Ktaoua y Primer Bani, debe de coincidir aproximadamente con el límite Dobrotiviense/Berouniense de la escala regional mediterránea, cuyas parti-cularidades bioestratigráficas han sido analizadas reciente-mente por Havlíccek y Vaněk (1996).

\section{Correlación internacional}

Volviendo al tema de la correlación de la sucesión marroquí con los estratotipos históricos del Sistema Ordovícico, el problema se había centrado hasta ahora en establecer los límites británicos equivalentes al Abereiddiense/Llandeiliense y Llanvirn/Caradoc, con arreglo a su reciente propuesta de redefinición cronoestratigráfica (Fortey et al., 1995). Sin embargo y como señala Webby (1998), la escala británica ha sido largo tiempo impuesta de facto como una lengua franca para la correlación internacional del Ordovícico, pero jamás ha llegado a formalizarse ningún estratotipo global para sus diferentes divisiones, con vistas a erigirse en auténtica escala patrón internacional. Por ello, la cuestión hoy día ya no es correlacionar el Ordovícico marroquí con la escala regional británica, sino tratar de expresar estas relacio-nes en términos globales. En este sentido, la nueva Serie Ordovícico Medio, formalizada por la Subcomisión de Ordo-vícico (ICS-IUGS), se ha visto implementada recientemente con la definición del Piso Darriwiliense, comprendido a efectos de reconocimiento entre la base de la Biozona de Undulograptus austrodentatus y la base de la Biozona de Nemagraptus gracilis (Mitchell et al., 1997; Webby, 1998). Este primer piso global fue aprobado por la Subcomisión Internacional del Sistema Ordovícico, luego por la Comisión Internacional de Estratigrafía, y ratificado finalmente en 1997 por decisión u $\mathrm{n}$ ánime de la Unión Internacional de Ciencias Geológicas, quien lo ha hecho constar en la última Tabla Estratigráfica Internacional (IUGS, 2000). Por lo tanto, el piso Darriwiliense ha pasado a tener un alcance mundial, $y$ su extensión temporal supera ligeramente a la de la "serie Llanvirn" redefinida por Fortey et al. (1995), dado que englobaría además parte del Fenniense.

De todos modos y en lo que concierne al Anti-Atlas, la utilización de una escala regional mediterránea aporta mayor precisión a las correlaciones que la pretendida escala regional británica. A su vez, el conjunto litológico analizado en este trabajo (Formación Tachilla y Grupo Primer Bani), representaría esencialmente al Darriwilliense de la escala patrón del Sistema Ordovícico, con la sola excepción d e I a Formación Izegguirene, atribuida al Ordovícico Superior (Fig. 4). E Ordovícico Medio temprano (designado provisionalmente como "Volkhoviense": Webby, 1998) estaría sustituido en el Anti-Atlas por una laguna estratigráfica equivalente a casi todo el Fenniense y a parte del Whitlandiense británico. Esta laguna queda sellada por la discontinuidad 
basal de la Formación Tachilla, cuya naturaleza varía entre una paraconformidad y una auténtica discordancia, dependiendo de las diferentes regiones del Anti-Atlas (Destombes et al., 1985).

El límite Ordovícico Medio/Ordovícico Superior lo he-mos situado tentativamente hacia la base de la Formación Izegguirene (Dobrotiviense superior tardío), por debajo del primer horizonte conteniendo Marrolithus cf. bureaui (OEHLERT) que se localiza a tan sólo $20 \mathrm{~m}$ del contacto con la Formación Ouine-Inirne (Anti-Atlas central, localidad 1695). La extensión vertical del trilobites citado es paralela a la de la Biozona de Lagenochitina ponceti, caracterizada igualmente en la parte alta de la Formación Izegguirene (Elaouad-Debbaj, 1987, localidad 2433). Ambas unidades bioestratigráficas brindan en la Península lbérica y el Macizo Armoricano un diplográptido característico de la Biozona de Nemagraptus gracilis de graptolitos (GutiérrezMarco et al., 1999b; Gutiérrez-Marco -datos inéditos-).

\section{Relaciones paleobiogeográficas}

\section{Las asociaciones fosilíferas del Ordovícico Medio del}

Anti-Atlas poseen un marcado carácter mediterráneo, adscri-biéndose a la llamada "Calymenacean-dalmanitacean shelf fauna", la cual resulta característica de ambientes relativa-mente someros, y se desarrollaba en paleolatitudes elevadas de las plataformas del norte de Gondwana (Cocks y Fortey, 1988, 1990) y Perunica (Havlíček et al., 1994). En este contexto, casi todos los autores precedentes han señalado las grandes semejanzas paleontológicas existentes entre la For-mación Tachilla y la Formación Šárka de Bohemia, indicada por la existencia de numerosas especies comunes o estrecha-mente emparentadas de moluscos, braquiópodos y ciertos graptolitos (Sinuites sowerbyi, Selesinuites perneri, Tropi-dodiscus pusillus, Ptychonema marocanum/P. desideratum, Lesueurilla prima, Cyrtodiscus nitidus, R. deshayesi/R. bohemica, Pauxillites pauxillus ssp., Gompholites cinctus, Euorthisina minor, Corymbograptus? retroflexus). La mayor parte de las formas mencionadas no se conocen en las "Capas con Tristani" contemporáneas del suroeste de Europa. Ello implica la existencia de ambientes sedimentarios probable-mente algo más profundos en el Anti-Atlas que en Ibero-Armórica, con neto predominio de las "biofacies de Colpo-coryphe" frente a las "biofacies de Neseuretus" (ambas en el sentido de Vidal, 1996) durante la mayor parte del depósito de la Formación Tachilla.

La aparición de ejemplares resedimentados de Neseuretus, Eohomalonotus y Plaesiacomia, a s í como de distintas especies de otros grupos comunes con Ibero-Armórica, comienza a ser frecuente a partir del tramo terminal de la Formación Tachilla y, sobre todo, se manifiesta en las distintas unidades del Grupo Primer Bani. Entre los elementos más notables con vinculaciones ibero-armoricanas destacan algu-nos equinodermos (Calix spp., Phlyctocystis spp., Aristocys-tites, Oretanocalix, Aspidocarpus), moluscos (Cardiolaria beirensis, Hemiprionodonta lusitanica?, Coxiconchia, Ri- beiria pholadiformis), braquiópodos (Tissintia convergens, Tafilaltia), conodontos (Distomodus? cf. tamarae, Plectodina), ciertos ostrácodos (Reuentalina aff. queneaui) y algunos trilobites (Eohomalonotus spp., Iberocoryphe spp., Kerfornella, Eccoptochile cf. mariana). No obstante, las afinidades bohémicas también retornan episódicamente en el seno de intercalaciones de pizarras oscuras de la parte alta del Grupo Primer Bani, que corresponden a ambientes más offs-hore (con la aparición d e Degamella princeps o Marrolithus cf. bureaui, por ejemplo).

Con todo, la aparentemente menor diversidad taxonómica del Ordovícico Medio del Anti-Atlas, con respecto a sus asociaciones coetáneas de otras regiones del norte de Gond-wana, puede imputarse a causas paleoclimáticas, debido a la vinculación d e I a $r$ e g i ón con un contexto circumpolar de aguas claramente más $\mathrm{f} r$ ías. Por ello, tampoco resulta extraño la existencia de numerosos endemismos entre los artrópodos (especies antiatlásicas de trilobites Phacopina y ostrácodos Paleocopa), así como géneros endémicos de equinodermos (Isidalocystis, Eumitrocystella), braquiópodos (Atlantida, Paterorthis, a f f . "Orthambonites") o moluscos (Quasisinuites), entre otros. Otra interpretación complementaria es la adscripción paleogeográfica de Marruecos a una paleolongitud bien diferenciada de la de la Península Ibérica durante el Ordovícico. En este sentido, Gutiérrez-Marco et al. (2002) ubican tentativamente al Dominio Ibérico en el margen pasivo de Gondwana comprendido entre el NE del Sahara argelino, Libia y Arabia Saudita, con cuyos territorios encuentran relaciones paleobiogeográficas más significativas que con Marruecos para el rango Ordovícico Medio a Silúrico inferior inclusive.

Desde el punto de vista de la dinámica faunística perigondwánica, los materiales del límite Oretaniense/Dobrotiviense y los del Dobrotiviense basal tienen gran interés, localizándose respectivamente en la parte media y alta de la Fm. Bou-Zeroual. En ellos se sitúa el registro más antiguo de algunos taxones que van a alcanzar una cierta difusión pos-terior en el ámbito peri-gondwánico. Tal es el caso de los diplopóridos Aristocystites y Phlyctocystis, presentes en ma-teriales Dobrotivienses del suroeste de Europa, migrando el primero a Perunica en el Berouniense (Gutiérrez-Marco y Baeza, 1996; Gutiérrez-Marco et al., 1999b). La aparición del trilobites facópido Morgatia (M.? rochi, del Oretaniense superior) también podría preceder al primer registro europeo de dicho género ( $M$. primitiva HAMMANN, del Dobroti-viense inferior). El mismo sentido migratorio se repite con el ostrácodo Piretopsis (Cerninella) bohemica, cuyo registro marroquí (Dobrotiviense terminal/ Berouniense basal) anti-cipa su aparición en Bohemia (Formación Viniče: Berou-niense). El resto de los organismos pelágicos, comunes con Bohemia, mantiene aproximadamente una presencia coetánea en el norte de África, así como los organismos bentónicos vinculados con condiciones ambientales concre-tas (sustratos arenosos y energéticos), que atestiguan relacio-nes más estrechas con Ibero-armórica (Henry y Destombes, 1991). No obstante, en el Oretaniense superior y Dobroti- 
viense basal del Anti-Atlas perviven algunos elementos desa-parecidos tiempo atrás en el suroeste europeo, como por ejemplo el género Bathycheilus (trilobites) y algunos morfo-tipos de braquiópodos de costillas gruesas ("Orthambonites" fraternus). Lo mismo sucede con el diplopórido Calix cor-nuta, cuyo registro africano más moderno data del Dobroti-viense superior (parte alta de la Formación Ouine-Inirne), en tanto que en la Península Ibérica desaparece en el Dobroti-viense basal.

\section{Conclusiones}

Se realiza un inventario de todos los fósiles identificados hasta el presente en las formaciones del Ordovícico Medio del Anti-Atlas marroquí, que actualizados taxonómicamente suman un mínimo de 36 formas diferentes de trilobites, 29 moluscos, 24 equinodermos, 10 graptolitos, 9 braquiópodos, 16 conodontos y ostrácodos, numerosos microfósiles de pa-red orgánica y representantes de otros grupos fósiles (brio-zoos, conuláridos, machaeridios) e icnofósiles, por el mo-mento mal caracterizados. Sus localidades de procedencia reúnen un total de 186 yacimientos $u$ horizontes paleontoló-gicos, que han sido reexaminados, principalmente, partiendo de los estudios inéditos de Destombes (1983a, 1983b, 1983c, 1985, 1987, 1988, 2000, 2001, 2002).

La revisión paleontológica y litoestratigráfica de las localidades fosilíferas aporta muchas novedades con respecto a la síntesis precedente (Destombes in Destombes et al., 1985), ya que amplía y depura considerablemente la lista taxonó-mica, y reasigna la posición estratigráfica correcta de muchos horizontes y estratotipos de taxones, que habían sido citados de forma contradictoria en publicaciones previas (Apéndice 1). El nuevo inventario taxonómico general, pretende ser de utilidad a los estudios biogeográficos y evolutivos relativos al Ordovícico perigondwánico. Pero además de la lista de fósi-les aportada para cada unidad litoestratigráfica, existen otros taxones citados e ilustrados para el Anti-Atlas, de los que se ignora su posición estratigráfica concreta. Tal es el caso de los trilobites Panderia y Uralichas?, citados, respectivamente, como "Illaenus sp., Llandeilo de Alnif" en Termier y Termier (1950c: lám. 193, fig. 23; col. Clariond), y como "hipostoma indeterminado, Llandeilo de Tafilelt" en idéntico trabajo y colección (Termier y Termier, 1950c: lám. 194, fig. 8). También del bivalvo Alnifia clariondi TERMIER y TERMIER (1950b: lám. 176, Fig. 1-3), caracterizado por sus descubridores en el "Llandeilo del JebelAlnif". Sin embargo, no puede descartarse que las localidades mencionadas perte-nezcan en realidad a la Formación Ktaoua Inferior (Ordoví-cico Superior), lo cual exige más investigaciones. Otro ejem-plo carente de adscripción litoestratigráfica es la forma inédita de estilóforo, muy semejante a Domfrontia pissoten-sis (CHAUVEL y NION), la cual es citada, sin más precisio-nes, en el "Llandeilo de Marruecos" (Lefebvre y Vizcaïno, 1999: p. 440). Entre los icnofósiles Eione, Diplichnites, Rusophycus, Palaeophycus y Rosellia, entre otros, fueron identificados por los autores en diversos afloramientos indiferenciados del Grupo Primer Bani en el Anti-Atlas oriental.

De cualquier modo, los ejemplos anteriores revelan que la biodiversidad del Ordovícico Medio del Anti-Atlas marroquí es, probablemente, bastante superior a la que apuntan las citas recogidas hasta ahora en la bibliografía y en el presente trabajo. En este sentido, resta por completar el conocimiento de grupos taxonómicos clave, tales como los graptolitos o grupos enteros de trilobites (asáfidos, ilénidos, trinucleidos, queirúridos...). También de otros grupos fósiles que, o bien no han sido nunca estudiados, o sobre ellos la investigación se halla en sus inicios. Entre éstos cabe destacar los cefaló-podos, rostroconchas, conuláridos, briozoos, ostrácodos, co-nodontos, etc.

El marco cronoestratigráfico del Ordovícico Medio del Anti-Atlas es asimilado en este trabajo con la escala patrón mediterránea, que se aplica por vez primera para correlacio-nar y caracterizar sucesiones norteafricanas. La problemática intrínseca de los estratotipos regionales británicos del Sis-tema Ordovícico, unido a la existencia de numerosos ende-mismos paleontológicos, favorecen una correlación prima facie con sucesiones mejor comparables de Ibero-Armórica y Bohemia.

Los trabajos publicados en los últimos quince años mostraban también serias discrepancias en cuanto a la corre-lación del Grupo Primer Bani con respecto a las formaciones bohémicas (Fig. 4), que ahora se revisan, proponiendo la correlación del limite inferior del Dobrotiviense con la parte media de la Formación Bou-Zeroual. Futuros estudios permitirán precisar con mayor detalle aquellos cronorregistros clave para la subdivisión interna del Oretaniense y Dobrotiviense en el Anti-Atlas, presentados en este trabajo de forma provisional. El grado de resolución en las correlaciones po-drá incrementarse además a medida que se vayan produ-ciendo nuevos hallazgos significativos en áreas perigondwá-nicas relacionadas. A modo de ejemplo, B. Lefebvre (com. escr. 2000) ha encontrado recientemente el estilóforo Aspi-docarpus cf. discoidalis (CRIPPS) en la parte superior de la Formación de Postolonnec del Macizo Armoricano, en unos niveles sensiblemente equivalentes a los del estratotipo del taxón en el Anti-Atlas (Dobrotiviense superior a la par que Darriwiliense terminal, Formación Ouine-Inirne).

Desde el punto de vista biogeográfico, el Ordovícico Medio del Anti-Atlas corresponde a la provincia nord- gondwaniense ("subprovincia marroquí" de Destombes in Destombes et al., 1985: p. 221), observándose unas afinidades bohémicas más notorias en la Formación Tachilla, y más próximas al suroeste de Europa para el Grupo Primer Bani. Ambas son consecuencia de cambios en las circunstancias ambientales vinculados con la evolución sedimentaria de toda la región. En el Anti-Atlas, la "transgresión global del Llanvirn" debuta en el Arenigiense (Fenniense terminal) y Oretaniense inferior, disipándose pronto con la instauración de medios progresivamente más someros hacia el Oretaniense superior y Dobrotiviense, asociados a sus respectivas biofacies. No obstante, los estudios biogeográficos requieren completar la revisión detallada de numerosos grupos taxonó- 
micos, que aportarán presumiblemente valiosos datos adicio-nales. Ello posibilitará depurar algunas identificaciones anó-malas como, por ejemplo, las referencias a formas típicamente laurénticas (Quadrijugator permarginatus), o bien exclusivamente bálticas (Sigmoopsis platyceras, $S$. sch-midti), que permanecen citadas entre los ostrácodos del Anti-Atlas, desvirtuando el marco biogeográfico general.

\section{Agradecimientos}

Este trabajo es una contribución al proyecto 410 ("The Great Ordovician Biodiversification Event") del Programa Internacional de Correlación Geológica (IUGS-UNESCO). Parte de las investigaciones de campo fueron financiadas con cargo al proyecto "El Ordovícico de Marruecos y sus relacio-nes gondwánicas con la Península Ibérica" (1994-1995), perteneciente al Convenio de Cooperación Bilateral entre el CSIC español y el CNCPRST marroquí. A la codirectora del mismo, Dra. Naïma Hamoumi (Universidad Mohammed V, Rabat), le agradecemos las facilidades brindadas entonces, así como la revisión c rítica del presente manuscrito. También a los revisores científicos Dres. Neil McDougall (Robertson Research Int. Ltd., Conwy) y Enrique Villas (Universidad de Zaragoza), cuyas sugerencias fueron muy oportunas de cara a la presentación final del texto. Vaya igualmente nuestro agradecimiento al Dr. Bertrand Lefebvre (Universidad de Dijon), por sus informaciones (en parte inéditas) sobre los estilóforos marroquíes y armoricanos, así como a los Dres. Enrique Bernárdez (Madrid) y Rafael Lozano (IGME, Ma-drid), por la realización de las ilustraciones de línea. En la redacción de los textos ingleses fuimos auxiliados por D. Manuel Regueiro (IGME, Madrid). La colaboración deGFA se inscribe en el proyecto "Dinámica faunística perigondwá-nica" del Programa de Cooperación Científica con Iberoamé-rica, promovido por el Gobierno español, así como en un subsidio de investigación otorgado por la Fundación Antorchas, República Argentina.

\section{Apéndice. Localidades paleontológicas del Ordovícico Medio del Anti-Atlas}

En la presente relación, todos los yacimientos paleontoló-gicos aparecen designados con el número original que les atribuyó Destombes, según datos recogidos de sus propias publicaciones y de las de otros autores que estudiaron parte de su colección d e fósiles. El número de cada yacimiento va seguido por una breve descripción geográfica (nombre del paraje, situación con respecto a poblaciones importantes) y, entre paréntesis, su ubicación precisa con arreglo a las Hojas del Mapa Topográfico de Marruecos, tanto a escala 1:100.000 ( $\left.{ }^{*}\right)$ como a escala 1:200.000 $\left(^{(*}\right)$, de las que se indica su denominación y las coordenadas Lambert para cada punto fosilífero. Sigue la información correspondiente a la unidad litoestratigráfica en la que se ubica el yacimiento, y las fuentes bibliográficas relativas a cada localidad. En casos concretos se resaltan, también, las discrepancias advertidas con respecto a otras asignaciones estratigráficas, previas a la presente revisión.

- 15: A ït Isi Oul o Aït Isfoul (Sidi Touhama), al SO de Zagora (El Glo*, Zagora**: $x=419,95 ; y=342,7$ ). Fm. Guezzart, aproximadamente $115 \mathrm{~m}$ por encima de la base. Havlíccek (1970, 1971), Destombes (1983a, 1988).

- 16: Oued el Guettara, al SE de Bou-Rbia (El Glo*, Zagora $\left.^{* *}: x=419,85 ; y=342,7\right)$. Fm. Guezzart, aproximadamente $90 \mathrm{~m}$ por encima de su base. Chauvel (1966), Destombes (1983a, 1988).

- 19: Bou Rbia-Sidi Touhama (El Glo**, Zagora**: $x=418,1$; $y$ $=343,7)$. Mitad superior de la Fm. Bou-Zeroual, aproximadamente $120 \mathrm{~m}$ por encima de la base. Destombes (1983a, 1988).

- 20: Cerca de la pista Bou Rbia-Sidi Touhama por el Oued elGuettara, en la región d e A ït Isi Oul al SO de Zagora (EI Glo'*, Zagora**: $x=418,15 ; y=343,75-80$ ). Mitad superior de la Fm. Bou-Zeroual, $115 \mathrm{~m}$ por en-cima de su base (horizonte atribuido a la "Fm. Kissane" por Havlíc"ek en 1971, y a I a F m . T addrist por Destombes en 1972). Havlíček (1971), Destombes (1972, 1983a, 1988), Marek (1983), Chauvel (1978), Horný (1997b).

- 39: Jbel Rhart, al $\mathrm{N}$ de Tizi $\mathrm{n}$-Tafilalt y al ENE de Zagora (Zagora $^{* * *}: x=479,7 ; y=382,6-383$ ). Parte media de la Fm. Guezzart, aproximadamente $35 \mathrm{~m}$ por encima de la base. Chauvel (1978, considerada por error como techo de la Fm. Bou-Zeroual), Destombes (1983a,

1988).

- 51: Touna n'larabene (= Arhembou n'Ourti), cerca del Jbel Adoumaz al $\mathrm{N}$ de Zagora (Tazzarine ${ }^{*}$, Jbel Sa-rhro**: $\mathrm{x}=$ 453,850; $y=405,150)$. Fm. Guezzart, aproximadamente $10 \mathrm{~m}$ por encima de su base. Chauvel (1966, 1978), Destombes (1983a, 1983c).

- 52: Touna n'larabene (= Arhembou n'Ourti), cerca del Jbel Adoumaz al $\mathrm{N}$ de Zagora (Tazzarine*, Jbel Sa-rhro**: $\mathrm{x}=$ $456,6 ; y=405,4)$. Parte inferior de la Fm. Tachilla. Destombes (inédito).

- 68: Flanco $\mathrm{N}$ de Jbel Kissane, al sur del macizo precám-brico del Jbel Sarhro (Agdz ${ }^{*}$, Jbel Sarhro**: $x=410,7 ; y=413,5$ ). Fm. Tachilla, parte baja, justo encima de la capa ferruginosa que se sitúa a $10 \mathrm{~m}$ de la base. Destom-bes (1983c).

- 100: Jbel Mtemellali (región de El Fecht-lkourbib-Maider) (Msissi $^{*}$, Todrha $^{* *}$ : $\left.x=580 ; y=97,95\right)$. Base de la Fm. Tachilla. Destombes (inédito).

- 154: Aori Amjot, al $E$ de Aït Saadane y O d e M a ïder (Tarhbalt*, Maïder ${ }^{* *}: x=526 ; y=423$ ). Formación Guezzart. Chauvel (1966, 1978), Destombes (1985).

- 156: E d e A ït Saadane, en el Macizo del Arhouri Amejout (Tarhbalt*, Maïder $\left.{ }^{* *}: x=524,9 ; y=424,45\right)$. Techo de la Fm. Ouine-Inirne. Destombes (1972, 1985).

- 168: S E d e A it Saadane, al O de Maïder (Tarhbalt*, Maïder $\left.{ }^{\star *}: x=526,2 ; y=424,4\right)$. Techo Fm. Tachilla. Destombes (1985). 
- 194: Adrar n'Oummawoun (Tasga-ou-Maoun) al E de Taghjijt, al $\mathrm{N}$ del Bani plegado (Anti-Atlas occidental) (Taghijt ${ }^{*}$, Foum el Hassane ${ }^{* *}: x=117,8 ; y=233,9$ ). Fm. Izegguirene. Destombes (1972, 2001).

- 196: Adrar n'Oummawoun (Tasga-ou-Maoun), Bani plegado (Taghjijt ${ }^{*}$, Foum el Hassane** $x=117,8 ; y=$ 233,9). Fm. Izegguirene. Destombes (inédito).

- 214: NO de Foum el Hassane, entre Amalou n'Boufsass y el Adrar Yousguerht (Taghjijt*, Foum el Hassane ${ }^{* *}: \mathrm{x}=$ 147,0; y = 240.4). Fm. Taddrist. Destombes (2001).

- 221: Anticlinal del Adrar Zougar. Anti-Atlas centrooccidental, región de Akka-Tata (Foum el Hassane* **, coordenadas no precisadas). Base de la Fm. Taddrist. Babin y Destombes (1990).

- 222: Adrar Azouggarh, S de Akka (Foum el Hassane* **: $x=191,9 ; y=227,8)$. Fm. Guezzart. Henry y Destombes (1991).

- 241: O de Akka (Akka***: $x=212,6 ; y=266,6)$. Base de la Fm. Guezzart. Destombes (2000).

- 242: O de Akka (Akka***: $x=212,6 ; y=266,7)$. Fm. Taddrist. Destombes (2000).

- 267: Kheneg (=Hassi) Brahim al O de Tata. Anti-Atlas centro-occidental, región de Akka-Tata (Tleta de Tagmoute*, Tata*: $x=240,55 ; y=302,40)$. Base de la Fm. Guezzart (Destombes, 2000), horizonte atribuido previamente a la Fm. Taddrist por Chauvel (1966).

\section{- 273: Cantil del Jbel Tamgounsa, al $O$ de Kheneg}

(= Hassi) Brahim. Anti-Atlas centro-occidental, región de Akka-Tata al SO de Tata (Tleta de Tagmoute ${ }^{*}, \mathrm{x}=$ $240,55 ; y=302,40)$. Fm. Bou-Zeroual. Babin y Destombes (1990-atribución errónea al tránsito Tachilla/Taddrist-), Horný (1997a, 1997b).

- 276: Adrar n'Tassefat, al E de Kheneg et-Tarfa (Tata* **: $x=290 ; y=310)$. Parte alta de la Fm. Bou-Zeroual. Destombes (2000).

- 277: Idem. loc. 276. Techo de la Fm. de Bou-Zeroual. Destombes (2000).

- 310: Orilla izquierda del estrecho de Foum-Zguit, flanco sur del Anti-Atlas central (Foum Zguit ${ }^{\star}$, Alougoum ${ }^{* *}: x=358,3$; $y=345,7)$. Afloramiento de la base de la Fm. Ktaoua Inferior (base del Miembro Ouaouglout), atri-buido previamente al techo de la Fm. Izegguirene (Des-tombes, 1972: lám. 7, fig. 10; Destombes, 1988: fig. 14 y p. 18 ) o al a parte alta del Grupo Primer Bani s.I. (Marek, 1983).

- 435: Idem. loc. 436.

- 436: $N$ de Touna n'larabene (= Arhembou n'Ourti), cerca del JbelAdoumaz al $\mathrm{N}$ de Zagora (Tazzarine*, Jbel Sarhro $\left.{ }^{* *}: x=456,6 ; y=405,4\right)$. Parte inferior de la Fm. Tachilla, unos $18-20 \mathrm{~m}$ por encima del horizonte 440 . Destombes (inédito), Elaouad-Debbaj, 1984, 1987 (= muestra micropaleontológica ZC 18).

- 437: Touna n'larabene (= Arhembou n'Ourti), cerca del Jbel Adoumaz al N de Zagora (Tazzarine*, Jbel Sa-rhro**: $x=455,7 ; y=405,6)$. Parte inferior de la Fm. Tachilla. Destombes (inédito).
- 438: Touna n'larabene (= Arhembou n'Ourti), cerca del Jbel Adoumaz al $\mathrm{N}$ de Zagora (Tazzarine*, Jbel Sa-rhro**: $\mathrm{x}=$ 455,68; y $=405,6)$. Parte inferior de la Fm. Tachilla. Destombes (inédito), Elaouad-Debbaj, 1984, 1987 (= muestra micropaleontológica ZC 19).

- 440: Touna n'larabene (= Arhembou n'Ourti), cerca del Jbel Adoumaz al $\mathrm{N}$ de Zagora (Tazzarine*, Jbel Sa-rhro**: $\mathrm{x}=$ 459,$1 ; y=402,65$ ). Base de la Fm. Tachilla (aproximadamente $3 \mathrm{~m}$ por encima del horizonte de hierro oolítico). Destombes (inédito), Deunff, 1977 (= muestra paleontológica Z 19, asimilada por error al punto 438: fide Destombes in ElaouadDebbaj, 1984,

p. 80), Elaouad-Debbaj, 1984, 1987 (= muestra micropaleontológica ZC 17, Arenig superior).

- 441: Idem. loc. 440. Destombes (1983a).

- 442: P r óxima al punto 440, pero unos $7 \mathrm{~m}$ por encima de ese horizonte (Tazzarine*, Jbel Sarhro**: $x=459 ; y=$ 402,7). Destombes (inédito).

- 443-446: Idem. loc. 440. Destombes (inédito).

- 447: Idem. loc. 442. Destombes (inédito).

- 482: Jbel Zagora al E de Zagora (Zagora* ** $x=459,6$; $y=369,4)$. Parte media de la Fm. Bou-Zeroual, aproximadamente $90 \mathrm{~m}$ por encima de la base. Destombes (1983a), Elaouad-Debbaj (1987 -p. 39, fig. 15-).

- 487: $\mathrm{S}$ del Jbel Ouarzemimen al $\mathrm{S}$ de Agadir (Tiznit*, Tafraoute $\left.^{* *}: \mathrm{x}=100 ; \mathrm{y}=305,97\right)$. Parte basal de la Fm. Tachilla, unos metros por encima de la localidad 495- 497. Destombes (inédito).

- 488: $S$ del Jbel Ouarzemimen al $S$ de Agadir (Tiznit*, Tafraoute ${ }^{\star *}: \mathrm{x}=100 ; \mathrm{y}=306$ ). Parte basal de la Fm. Tachilla, unos metros por encima de la localidad 487, bajo una intercalación de cuarcita gris. Destombes (iné-dito).

- 489: Jbel Tachilla-Ouarzemine, al S de Agadir (Tiznit*,

Tafraoute $\left.{ }^{* *}: x=99,3 ; y=306,7\right)$. Parte inferior de la Fm. Tachilla, $80 \mathrm{~m}$ por encima de la base, por encima de un pequeño horizonte de hierro oolítico. Destombes (inédito), Elaouad-Debbaj $(1984,1987)$.

- 491: $S$ del Jbel Ouarzemimen al $S$ de Agadir (Tiznit*, Tafraoute $\left.{ }^{\star *}: x=98,9 ; y=307,3\right)$. Parte inferior de la Fm. Tachilla. Destombes (inédito).

- 493-494: Idem. loc. 487. Destombes (inédito).

- 495-496: Idem. loc. 497 y 505. Destombes (inédito).

- 497: Jbel Tachilla-Ouarzemine, al S de Agadir (Tiznit* Tafraoute $\left.^{\star *}: x=101,8 ; y=306,7\right)$. Extrema base de la Fm. Tachilla. Destombes (inédito). Elaouad-Debbaj (1984, 1987).

- 499: Jbel Ouarzemimen, cerca de Assaka, Macizo de Tachilla (Tiznit*, Tafraoute $\left.{ }^{\star *}: x=99,4 ; y=308\right)$. Parte alta de la Fm. Tachilla. Chauvel (1966)

- 505: Jbel Tachilla-Ouarzemine, al S de Agadir (Tiznit*, Tafraoute $\left.^{\star *}: x=102 ; y=306,5\right)$. Extrema base de la Fm. Tachilla. Destombes (inédito).

- 521: Adrar Imestane, Anti-Atlas occidental (Bou Izar$k^{*}{ }^{*}$, Goulimine $\left.{ }^{* *}: x=98,0 ; y=240,0\right)$. Parte inferior de la Fm. Tachilla. Destombes (2001). 
- 534: Kheneg Infguene (Sidi Salah), entre Foum el Has-sane y Assa; parte meridional del Bani plegado (Assa* ${ }^{* *}: x=124,5$; y $=205,8)$. Fm. Ouine-Inirne. Destombes (2001).

- 535: Kheneg Infguene (Sidi Salah), entre Foum el Has-sane y Assa; parte meridional del Bani plegado (Assa* ${ }^{* *}: x=124,5$; $y=205,8)$. Fm. Izegguirene. Henry y Destombes (1991), Destombes (2001).

- 559: Jbel Aroudane al $S$ de Taouz, Tafilalt meridional (Taouz Est $^{*}$, Taouz $\left.^{* *}: x=467,3 ; y=430,6\right)$. Fm. Izeg-guirene. Henry y Destombes (1991).

- 561: Amalou n'Boufsass, Jbel Irhir n'Ouadou, en el Bani plegado (Anti-Atlas occidental) (Taghjijt*, Foum el Hassane ${ }^{\star *}$ : $x=144,7 ; y=239,5)$. Fm. Bou-Zeroual, localidad atribuida previamente al techo de la Fm. Ta-chilla. Chauvel (1966), Babin y Destombes (1990), Des-tombes (2001).

- 563: Pista Tilemsoun-Messeied, en el Jbel Zini al $S$ de Tantane (prov. de Tarfaya, Anti-Atlas suroccidental) (Goulimine $^{* *}$ : $\left.x=317 ; \quad y=155,4\right)$. Base de la Fm. Tachilla. Dean (1966), Vidal (1996), Horný (1997b).

- 568: $N$ de Alnif (Alnif ${ }^{\star}$, Todhra**: $x=520,4 ; y=59$ ). Techo de la Fm. Guezzart. Destombes (1985).

- 570: Anti-Atlas suroccidental (Goulimine** $\mathrm{x}=357$; $\mathrm{y}=$ 161). Grupo Primer Bani (fósiles sueltos -"Ogy-giocaris henningsmoeni?"-, formación indeterminada). Destombes (inédito).

- 572: Oeste de Aouinet Torkoz, Anti-Atas occidental (Fask*, Taidalt**: $x=1113,5 ; y=767,6)$. Parte media del Grupo Primer Bani (formación indeterminada). Des-tombes (2002).

- 573: Kheneg M'Karz, Anti-Atlas occidental (Gouli-mine*, Taidalt**: $x=1072,85 ; y=761,7)$. Parte alta de la Fm. Tachilla. Destombes (2002).

- 575: $9 \mathrm{Km}$ al $\mathrm{E}$ de Kheneg M'Karz, Anti-Atlas occiden-tal (Goulimine*, Taidalt ${ }^{\star *}: x=355 ; y=160$ ). Grupo Primer Bani (indiferenciado). Destombes (2002).

- 581: Jbel Aroudane, al $S$ de Taouz (Taouz Est*, Taouz $\left.^{* *}: x=637,1 ; y=429,6\right)$. Probablemente Fm. OuineInirne, alternativamente en la Fm. Izegguirene. Destombes (1987), Henry y Destombes (1991).

- 582: Irhil n'Achich al E de Tazzarine, Jbel Talrhoumt (Tarhbalt*, Maïder ${ }^{\star *}: x=494,7 ; y=425,3$ ). Parte supe-rior de la Fm. Ouine-Inirne. Destombes (1985).

- 593: Jbel Tachilla, al $S$ de Agadir (Tiznit*, Tafraoute** $x=$ 108,2; $y=331,5)$. Grupo Primer Bani indiferen-ciado. Chauvel $(1966,1978)$.

- 598: Taskala, Anti-Atlas occidental (Goulimine*, Tai-dalt**: $x$ $=1103,3 ; y=769,0)$. Base de la Fm. Tachilla. Destombes (2002).

- 602: Entre Taskala y Torkoz, Bani plegado (Anti-Atlas centrooccidental) (Fask ${ }^{*}$ Taidalt $\left.{ }^{\star *}: \mathrm{x}=1113,5 ; \mathrm{y}=767,5\right)$. Fm. Taddrist. Babin y Destombes (1990), Destombes (2002).

- 605: Jbel Segdit, $5 \mathrm{~km}$ al S de Torkoz (Bani plegado, AntiAtlas centro-occidental) (Taidalt*, coordenadas no precisadas). Fm. Ouine-Inirne, localidad atribuida previamente a la Fm. Guezzart (Babin y Destombes 1990: Fig. 2).

- 609: Jbel Aroudane, cerca de Taouz, Anti-Atlas oriental (Taouz Est $^{*}$, Taouz $\left.{ }^{* *}: x=636,5 ; y=430,4\right)$. Techo Fm. Izegguirene. Havlíccek (1970: ex Fm. Ouine-Inirne; 1971), Destombes (1987).

- 615: Jbel Injar, Tafilalt oriental (Hassi Beraber*; $x=645,5 ; y=$ 87,9). A 150 m por encima de la base del Grupo Primer Bani (indiferenciado), probablemente Fm. Izegguirene. Destombes (1987).

- 621: Jbel Bou Legroun, Tafilalt occidental (Erfoud ${ }^{*}$, Tafilalt ${ }^{\star *}: x$ $=596,1 ; \mathrm{y}=85,6)$. Parte basal del Grupo Primer Bani, localmente indiferenciado. Destombes (1987).

- 627: Tizi n'Tanoumrhit, SE de Nekob (Jbel Sarhro**: $x=$ $464,7 ; y=424,850)$. Parte media de la Fm. Guezzart. Chauvel (1966), Destombes (1983c).

- 629: Jbel Izegguirène, al $S$ de Nekob (Tazzarine*, Jbel Sarhro**: $x=465 ; y=422)$. Fm. Izegguirene, $5 \mathrm{~m} \mathrm{p}$ o $\mathrm{r}$ encima de la base. Destombes (1983c).

- 631: Izegguirene, entre Tizi n'Tanoumrhit y Tanoum-rhit, SE de Nekob (Tazzarine ${ }^{*}$, Jbel Sarhro**: $x=465,6 ; y=423,3-5$ ). Parte inferior de la Fm. Izegguirene, $65 \mathrm{~m}$ por encima de la base. Chauvel (1966, 1978), Destom-bes (1983c).

- 633: Jbel Izegguirène, al $S$ de Nekob (Tazzarine*, Jbel Sarhro*: $x=465,55 ; y=423,3)$. Fm. Izegguirene, $30 \mathrm{~m}$ por encima de la base. Destombes (1983c).

- 665: Kheneg M'Karz, Anti-Atlas occidental (Gouli-mine*, Taidalt**: $x=1073,6 ; y=764,4)$. Base de la Fm. Tachilla. Destombes (2002).

- 714: Imini, al NO de Ouarzazate. Flanco S del Alto-Atlas centro-occidental (sona subatlásica meridional)(Telouet*, coordenadas no precisadas). Parte terminal de la Fm. Tachilla. Destombes (1988), Babin y Destom-bes (1990).

- 729: Jbel Taddrist entre Tansikht y Nekob (Agdz*, Jbel Sarhro $\left.{ }^{* *}: x=442,1 ; y=418,8\right)$. Parte inferior de la Fm. Tachilla, aproximadamente $35 \mathrm{~m}$ por encima de la base. Destombes (1983a, 1983c).

- 733: Jbel Taddrist entre Tansikht y Nekob (Agdz*, Jbel Sarhro**: $x=442,1 ; y=418,7)$. Parte media-baja de la Fm. Tachilla, aproximadamente $55 \mathrm{~m}$ por encima de la base. Destombes (1983a, 1983c).

- 734: Jbel Taddrist entre Tansikht y Nekob (Agdz ${ }^{*}$, Jbel Sarhro**: $x=442,1 ; y=418,2$ ). Parte superior de la Fm. Tachilla, aproximadamente $135-140 \mathrm{~m}$ por encima de la base. Destombes (1983a, 1983c).

- 736: Jbel Taddrist, al S del macizo precámbrico del Jbel Sarhro (Agdz $^{*}$, Jbel Sarhro**: $\left.x=442,1 ; y=418,1\right)$. Parte baja de la Fm. Taddrist, unos $10 \mathrm{~m}$ por encima de la base. Destombes (1983a, 1983c).

- 737: Jbel Taddrist, al S del macizo precámbrico del Jbel Sarhro $\left(\right.$ Agdz $^{*}$, Jbel Sarhro**: $\left.x=442,1 ; y=418,05\right)$. 
Parte baja de la Fm. Taddrist, unos 15-16 m por encima de la base. Destombes (1983a, 1983c).

- 755: Jbel Izeggirène al $S$ de Nekob (Tazzarine*, Jbel Sarhro*: $x=471,5-6 ; y=423,5-424)$. Parte media de la Fm. Izegguirene, unos $55 \mathrm{~m}$ por encima de la base. Chauvel (1971, 1978), Destombes (1983c).

- 846: Jbel Aroudane, al $S$ de Taouz (Taouz Est*, Taouz $\left.{ }^{* *}: x=638,7 ; y=426,1\right)$. Tercio inferior del Grupo Primer Bani (localmente indiferenciado). Des-tombes (1987).

- 852: Jbel Tijekht (Taouz Ouest ${ }^{\star}$, Taouz $^{\star *}: x=613,3 ; y=$ 427). Fm Tachilla. Destombes (1987).

- 878: Macizo del Aori Amjot, directamente al E de Taz-zarine (Tarhbalt*, Maïder**: $x=526,2 ; y=427,7$ ). Techo de la Fm. Ouine-Inirne. Destombes (1972, 1985).

- 950: Hassi Brahim, Región de Akka-Tata (Tleta de Tag-moute*, Taliouine $\left.{ }^{\star *}: x=240,55 ; y=302,4\right)$. Grupo Primer Bani, probablemente Fm. Guezzart. Marek (1983).

- 967: Jbel Bou Isidane, al $S$ de Alnif $\left(\right.$ Maïder $^{* *}: \mathrm{x}=$ $523,15 ; y=445,5)$. Mitad superior de la Fm. Izeg-guirene. Chauvel (1966), Destombes (1985).

- 1050: Arhembou n'Dali e Ikhf n'Ourarh al S de Tinerhir, flanco $\mathrm{N}$ del macizo precámbrico del Jbel Sarhro (Al-nif*, Todhra**: $\mathrm{x}$ $=507,2 ; y=84,4)$. Parte baja de la Fm. Tachilla, unos $12 \mathrm{~m}$ por encima de la capa de hierro basal. Havlíc ${ }^{\nu}$ ek (1971), Destombes (1972, 1985), Marek (1983), Babin y Destombes (1990), Horný (1997b).

- 1065: Isk-Tanotjane en Amerdoul n'Oufsad, flanco $\mathrm{N}$ del Jbel Sarhro al S de Tinerhir (Alnif*, Todhra**: $x=499,2 ; y=87,6$ ). Parte baja de la Fm. Tachilla. Destombes $(1972,1985)$

- 1193: NO de Foum el Hassane, entre Amalou n'Bouf-sass y el Adrar Yousguerht (Taghjijt*, Foum el Has-sane ${ }^{* *}: \mathrm{x}=$ $144,6 ; y=239,6)$. Fm. Taddrist. Destombes (2001).

-1212-1213: Jbel Bou Lagadi, en el Tafilalt occidental (Erfoud*, Tafilalt**: $x=596,5 ; y=89,8)$. Fm. Tachilla. Detombes (1972, 1987).

- 1218: Koudra Maha (= Koudiat Maha), en el Tafilalt occidental (Erfoud $^{*}$, Tafilalt ${ }^{* *}$ x $\left.=593,2 ; y=92,8\right)$. Fm. Tachilla. Destombes $(1972,1987)$.

- 1230: Jorf ed Dal (= Jorf Dahl), en el Tafilalt occidental (Erfoud $^{*}$, Tafilalt**: $\left.x=585,8 ; y=95,2\right)$. Fm. Tachilla. Marek (1983), Destombes (1987).

- 1233: Foum ou Taouch, Tafilalt occidental (Erfoud ${ }^{*}$, Tafilalt ${ }^{\star *}: x$ 585,9; y = 89). Fm. Tachilla. Destombes (1987).

- 1236: Jbel Bou Legroun, Tafilalt occidental (Erfoud ${ }^{*}$, Tafilalt**: $x=596 ; y=86)$. Parte inferior de la Fm. Tachilla, unos 10-15 m por encima de la base. Destom-bes (1987), Horný (1997b).

- 1247: $\mathrm{T}$ a filalt oriental, al ESE del Macizo de Khabt el Hejar = Rabt-el-Hajar (Erfoud ${ }^{*}$, Tafilalt ${ }^{\star *}: x=589,8 ; y=80,6$ ). Fm. Tachilla. Destombes (1987), Horný (1997b).
- 1320: T a filalt oriental (Anti-Atlas oriental), al ESE del Macizo de Khabt el Hejar, bajo la Hamada cretácica (Erfoud*, Tafilalt $\left.{ }^{* *}: x=630 ; y=92,5\right)$. Fm. Tachilla. Havlíc ${ }^{2}$ ek (1971), Destombes $(1972,1987)$, Marek (1983), Babin y Destombes (1990), Horný (1997b).

- 1325: T a filalt oriental, al ESE del Macizo de Khabt el Hejar (Erfoud $^{*}$, Tafilalt**: $\left.x=631,1 ; y=92,4\right)$. Fm. Tachilla. Destombes $(1972,1987)$.

- 1347: T a filalt oriental, Rosfa el Kahla, al E y a I S E d e I Macizo de Rabt el Hajar (Hassi Beraber ${ }^{*}$, Tafilalt ${ }^{* *}: x=634,4$; y =90,1). Fm. Tachilla. Destombes (1972,

1987).

- 1363: T a filalt oriental, cerca de Hassi Injar el Foukani (Hassi Beraber $^{*}$, Tafilalt $\left.{ }^{\star *}: x=638,7 ; y=90,3\right)$. Fm. Tachilla. Destombes (1972, 1987), Marek (1983), Babin y Destombes (1990).

- 1385: T a filalt oriental, al E y a I S E de I Macizo de Rabt el Hajar (Hassi Beraber*, Tafilalt ${ }^{\star *}: x=649,6 ; y=89,8$ ). Fm. Tachilla. Destombes $(1972,1987)$.

- 1419: Tafilalt oriental, al E y al SE del Macizo de Rabt el Hajar (Hassi Beraber*, Tafilalt**: ${ }^{*}=649,2$; y = 89). Fm. Tachilla. Destombes (1987).

- 1421: T a filalt oriental, Jbel Injar (Hassi Beraber*, Tafi-lalt**: $x$ $=645,4 ; y=87,7)$. Parte superior del Grupo Primer Bani (indiferenciado), en el techo de un tramo de $20 \mathrm{~m}$ de areniscas. Destombes (1987).

- 1422: $T$ a filalt oriental, Jbel Injar (Hassi Beraber ${ }^{\star}$, Tafi-lalt ${ }^{\star \star}: \mathrm{x}$ $=644,7 ; y=87,4)$. Parte superior del Grupo Primer Bani (indiferenciado), en la base de un tramo de $20 \mathrm{~m}$ de areniscas. Destombes (1987).

- 1510: Adrar Rich Oua Libou, al S del Tafilalt (Erfoud ${ }^{*}$, Tafilalt**: $x=613,2 ; y=51,4)$. Fm. Tachilla. Destombes $(1972)$

1511: Rich Oua Libou, Tafilalt (Erfoud ${ }^{*}$, Tafilalt** $x=611,5$; y $=50,35)$. Parte superior del Grupo Primer Bani (indiferenciado). Destombes (1987).

-1512: Rich Oua Libou, Tafilalt (Erfoud ${ }^{*}$, Tafilalt**: $x=611,3 ; y$ $=50,3)$. Parte superior del Grupo Primer Bani, probablemente Fm. Izegguirene. Destombes (1987).

- 1518: Jbel Tadaout o Tijekht al O de Taouz, Tafilalt meridional (Taouz Ouest $^{*}$, Taouz $\left.{ }^{* *}: x=615,2 ; y=438,4\right)$. Pizarras verdes en el flanco $E$ de un anticlinal (parte basal del Grupo Primer Bani indiferenciado). Chauvel (1978), Destombes (1987).

- 1524: Jbel Tijekht al O de Taouz, Tafilalt meridional (Taouz Ouest $^{*}$, Taouz $\left.^{* *}: x=605,8 ; y=436,2\right)$. Base del Grupo Primer Bani. Destombes (1987).

- 1525: Jbel Tijekht al O de Taouz, Tafilalt meridional (Taouz ${ }^{\star *}$ : $x=600,6 ; y=427,7)$. Areniscas cuarzosas en el flanco $S$ de un anticlinal (Grupo Primer Bani indife-renciado). Chauvel (1978), Destombes (1987).

- 1527: Rich el Jdaïd en Jbel Tijekht, Macizo de Taouz, Tafilalt meridional (Taouz Ouest ${ }^{*}$, Taouz ${ }^{* *}: x=613,7 ; y=430,1$ ). Parte superior de la Fm. Tachilla. Havlíček 
(1971), Destombes (1972 -como base del Grupo Primer Bani-, 1987).

- 1528: Oued el Jdaïd al pie del Jbel Tijekht, Macizo de Taouz, Tafilalt meridional (Taouz Ouest*, Taouz ${ }^{* *}: x=615,3 ; y=$ 428,7). Parte superior de la Fm. Tachilla, por debajo de la localidad 1527. Destombes $(1972,1987)$, Marek (1983).

- 1529: Jbel Tijekht, Macizo de Taouz, Tafilalt occidental (Taouz Ouest $^{*}$; Taouz $\left.{ }^{\star *}: x=617,1 ; y=430,4\right)$. Parte superior de la Fm. Tachilla. Destombes (1987).

- 1570: Adrar n'Tassefat al $E$ de Kheneg et-Tarfa (Tata*: $x=$ $289,3 ; y=310,7)$. Parte baja de la Fm. Tachilla, pocos metros por encima de la base. Destombes (2000)

- 1571: Idem. loc. 1570 (Tata*: $x=289,6 ; y=310,4)$. Fm. Tachilla, $120 \mathrm{~m}$ por encima de la base. Destombes (2000).

- 1573: Jbel Bani, $8 \mathrm{~km}$ al $O$ de Agadir-Tissint (Tissint ${ }^{*}$, AgadirTissint $\left.{ }^{\star \star}: x=303 ; y=319,5\right)$. Parte basal de la Fm. Tachilla, unos $10 \mathrm{~m}$ por encima del nivel de hierro. Destombes (1988).

- 1574: Jbel Bani, 8 km al O de Agadir-Tissint (Tissint*, AgadirTissint $\left.{ }^{* *}: x=311,8 ; y=323,85\right)$. Fm. Tachilla. Destombes (1988).

- 1575: Jbel Bani, 8 km al O de Agadir-Tissint (Tissint*, AgadirTissint $\left.{ }^{* *}: x=311,9 ; y=323,8\right)$. Parte media de la Fm. Tachilla. Destombes (1988).

- 1576: Agadir-Tissint, al NO de Guezzart (Tissint*, AgadirTissint $\left.{ }^{* *}: x=311,95 ; y=323,75\right)$. Fm. Guez-zart. Havlícek $(1970,1971)$.

- 1585: Agadir-Tissint (Tissint ${ }^{*}$, Agadir-Tissint ${ }^{\star *}: x=308 ; y=$ 321,6). Fm. Guezzart. Havlíček (1970, 1971), Destombes (1988).

- 1591: Jbel Bani al O de Foum Zguit, flanco $S$ del Anti-Atlas central (Alougoum ${ }^{* *}$ : $x=350 ; y=349$ ). Fm. Guezzart (confundida previamente con la Fm. Taddrist). Havlíček $(1970,1971)$.

- 1597: Proximidades de la pista Bou Rbia-Sidi Touhama (Zagora $\left.^{* *}: x=418,15 ; y=343,5\right)$. Fm. Guezzart. Chau-vel (1978).

- 1598: Proximidades de la pista Bou Rbia-Sidi Touhama

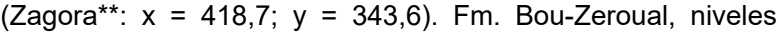
previamente atribuidos al tránsito entre las fm. Tachilla y Taddrist. Havlíček (1971), Chauvel (1978).

- 1599: Cerca de la pista Bou Rbia-Sidi Touhama por el Oued Guettara (Zagora**: $x=418,75 ; y=343,6$ ). Fm. Bou-Zeroual, niveles previamente atribuidos al tránsito entre las fm. Tachilla y Taddrist. Destombes (1972), Chauvel (1978).

- 1600: Ez Zbbouz, entre Zagora y Foum Zguit (El Gloa*, Zagora $\left.^{\star *}: x=418,9 ; y=344,1\right)$. Fm. Taddrist. Destom-bes $(1972,1983 a)$

- 1601: A ït Isfoul (= Aït Isi Oul) al $\mathrm{N}$ de Foum Hamia (= Foum el-Fehamya), O Tagounite, Anti-Atlas central (El Glo'*, Zagora**: $x=419,65 ; y=337,4)$. Parte superior de la Fm. Izegguirene, unos $80 \mathrm{~m}$ por encima de la base. Chauvel (1969), Destombes (1983a, 1988).
- 1602: Jbel Abbas, SE de Bou Rbia entre Zagora y Foum Zguit (El Gloa*, Zagora**: $x=426,5 ; y=336,8$ ). Cerca del techo de la Fm. Izegguirene, unos $95 \mathrm{~m}$ por encima de la base. Havlĩ̌cek $(1970,1971)$, Destombes (1983a,

1988).

- 1644: A ït Isfoul (= Aït Isi Oul) al $\mathrm{N}$ de Foum Hamia, $\mathrm{O}$ de Tagounite (Zagora***: $x=467,8 ; y=344,2$ ). Mitad inferior de la Fm. Izegguirene, por debajo de la localidad 1645. Destombes (1983a, 1988).

-1645: Frente a Foum Hamia, al O de Tagounite (Zagora* **: $x=$ $467,3 ; y=343,8)$. Parte media de la Fm. Izeg-guirene, unos $50 \mathrm{~m}$ por encima de la base. Destombes (1972, 1983a, 1988), Henry y Destombes (1991).

- 1695: Tizi n'Tanekfoult, Jbel Adoumaz al NNO de Za-gora (Tazzarine* $^{*}$ Jbel Sarhro**: $\mathrm{x}=453,7-453,95 ; \mathrm{y}=$ 413,1-412,7). Mitad inferior de la Fm. Izegguirene, unos $20 \mathrm{~m}$ por encima de la base. Destombes (1983a, 1983c), ElaouadDebbaj $(1987$, p. 36).

- 1696: Cercanías de Tizi n'Tanekfoult, NNO de Zagora (Tazzarine*, Jbel Sarhro**: $x=453,9 ; \quad y=413$ ). Parte superior de la Fm. Izegguirene. Chauvel (1978), Des-tombes (1983c).

- 1697: Tizi n'Tanekfoult, Jbel Adoumaz al NNO de Za-gora (Tazzarine $^{*}$, Jbel Sarhro*: $x=451,1 ; y=412,2$ ). Tercio superior de la Fm. Ouine-Inirne, a unos $125 \mathrm{~m}$ por encima de la base. Chauvel (1978), Destombes (1983a, 1983c).

- 1698: Tizi n'Tanekfoult, Jbel Adoumaz al NNO de Za-gora, (Tazzarine $^{*}$, Jbel Sarhro** $x=450,9 ; y=412,4$ ). Parte media de la Fm. Ouine-Inirne, a unos $80 \mathrm{~m}$ por encima de la base. Chauvel (1971), Destombes (1983a, 1983c), Cripps (1990), Beisswenger (1994).

- 1699: Arhembou n'ou Ourti, en la región de Adoumaz al $\mathrm{N}$ de Zagora (Tazzarine*, Jbel Sarhro**: $x=455,2$; $y=404,8$ ). Parte alta de la Fm. Taddrist, a unos $50 \mathrm{~m}$ por encima de la base. Chauvel (1978), Destombes (1983a)

- 1700: Arhembou n'ou Ourti, en la región de Adoumaz al $\mathrm{N}$ de Zagora (Tazzarine ${ }^{*}$, Jbel Sarhro** $x=455 ; y=404,8$ ). Parte baja de la Fm. Bou-Zeroual, unos $10 \mathrm{~m}$ por encima de la base. Chauvel (1978), Destombes (1983a, 1983c).

- 1763: Jbel Tagounit, entre Zaouïa Tafetchna y Tansikht (Agdz $^{*}$, Jbel Sarhro**: $\left.x=438,1, y=415,5\right)$. Tercio superior de la Fm. Ouine-Inirne. Chauvel (1978), Des-tombes (1983c).

- 1764: Jbel Tagounit, entre Zaouïa Tafetchna y Tansikht (Agdz $^{*}$, Jbel Sarhro**: $\left.x=437,8 ; y=415,6\right)$. Parte alta de la Fm. Guezzart, por encima de la localidad 1765. Chauvel (1966, 1978), Destombes (1983c), Gutiérrez-Marco et al. (1997).

- 1765: Jbel Tagounit, entre Zaouïa Tafetchna y Tansikht (Agdz $^{*}$, Jbel Sarhro**: $\left.x=438 ; y=415,8\right)$. Parte alta de la Fm. Guezzart. Chauvel (1966, 1978), Destombes (1983c). 
- 1772: Jbel Taddrist (Jbel Sarhro**: $x=443,1 ; y=$ 418,6). Fm. Taddrist o Guezzart (material suelto). Chauvel (1978).

- 1781: Tizi n'Aamoun, cerca de Nekob (Tazzarine*, Jbel Sarhro**: $x=454,5 ; y=424,6)$. Fm. Bou-Zeroual. Chauvel (1978 -atribuido a la Fm. Taddrist-), Destombes (1983c -asignado a la parte superior de la Fm. Guezzart-).

- 1782: Jbel Izegguirène, al $S$ de Nekob (Tazzarine*, Jbel Sarhro**: $x=454,7 ; y=418)$. Parte superior de la Fm. Izegguirene. Destombes (1983c).

- 1793: Irhil n'Achich-Jbel Talrhoumt al NE de Tazzarine, Anti-Atlas central (Tarhbalt*, Maïder ${ }^{\star *}: x=492,5$; $y=$ 429,45). Parte media de la Fm. Tachilla. Destombes (1985).

- 1794: Irhil n'Achich-Jbel Talrhoumt al NE de Tazzarine, Anti-Atlas central (Tarhbalt*, Maïder ${ }^{* *}$ : $x=492,5$; y $=492,45)$. Parte media de la Fm. Tachilla, aproximadamente a unos $60 \mathrm{~m}$ por encima de la base. Destombes (1985).

- 1795: Irhil n'Achich-Jbel Talrhoumt al NE de Tazzarine, Anti-Atlas central (Tarhbalt*, Maïder**: $\mathrm{x}=493$; $\mathrm{y}=$ 428). Techo de la Fm. Tachilla, entre 150-155 m por encima de la base, discordante bajo el nivel ferruginoso de Tourza (base de la Fm. Taddrist). Havlíček (1971), Chauvel (1978), Destombes (1985).

- 1797: Cantil de Izegguirene (Jbel Sarhro**: $x=470,1$; y =423,8). Fm. Izegguirene. Chauvel (1978).

- 1811: Pista entre Tazzarine y Alnif, por Aït-Saadane (Maïder**: $x=520, y=434,7$ ). Grupo Primer Bani (horizonte indiferenciado). Chauvel (1978).

- 1824: Jbel Ahchach-Jbel Bou Isidane, al $S$ de Alnif (Alnif*, Todrha**: $x=523,3 ; y=45,8)$. Mitad superior de la Fm. Izegguirene. Chauvel $(1971,1978)$, Destom-bes (1985).

- 1825: Al pie del Jbel Bou Isidane (= Jbel Isidal), sur de Alnif, Anti-Atlas oriental (Alnif* ${ }^{*}$ Todrha** $x=522 ; y=$ 45,8). Parte alta de la Fm. Ouine-Inirne, niveles próximos al techo. Destombes (1985), Babin y Destombes (1990).

- 1826: Jbel Bou Isidane (= Jbel Isidal), al $\mathrm{S}$ de Alnif (Alnif $^{*}$, Todrha**: $\left.x=521,5 ; y=45,8\right)$. Fm. Guezzart, localidad confundida en trabajos previos con la Fm. Taddrist. Chauvel (1971, 1978), Destombes (1985).

- 1867: Llanura de Azarar, entre Hassi Brahim y Akka (Tetla de Tagmoute*, Tata** $x=237 ; y=290,6)$. Parte media de la Fm. Bou-Zeroual. Chauvel (1978), Destombes (2000).

- 1868: Llanura de Azarar, entre Hassi Brahim y Akka (Tetla de Tagmoute $^{*}$, Tata** $x=236,8 ; y=290,6$ ). Techo de la Fm. Taddrist. Chauvel (1978 -atribuida a la base del grupo Primer Bani-), Destombes (2000).

- 1869: Llanura de Azarar, entre Hassi Brahim y Akka (Tetla de Tagmoute ${ }^{*}$ Tata $\left.^{* *}: x=236 ; y=290,2\right)$. Techo de la Fm. Tachilla. Chauvel (1978 -asignada a la base del Grupo Primer Bani-), Destombes (2000).
- 1870: Llanura de Azarar, entre Hassi Brahim y Akka (Tetla de Tagmoute*, Tata** $x=236,1 ; y=290,2$ ). Parte superior de la Fm. Tachilla. Destombes (2000).

- 1872: Llanura de Azarar, entre Hassi Brahim y Akka (Tetla de Tagmoute*, Tata** $x=235,6 ; y=290,2$ ). Tercio superior de la Fm. Tachilla. Chauvel (1978 -asignada a la base del Grupo Primer Bani-). Fm. Tachilla. Destombes (2000).

- 1873: Llanura de Azarar, entre Hassi Brahim y Akka (Tetla de Tagmoute*, Tata**: $x=235,2 ; y=290,5$ ). Parte media de la Fm. Tachilla. Destombes (2000).

- 1874: Llanura del Azarar, entre Hassi Brahim y Akka (Tetla de Tagmoute*, Tata**: $x=235,2 ; y=290,5)$. Fm. Tachilla. Chauvel (1978 -asignado a la base del Grupo Primer Bani-), Destombes (2000).

- 1876: cantil del Jbel Taouarda, entre Hassi Brahim y Akka (Tetla de Tagmoute $^{*}$, Tata**: $\mathrm{x}=240,6 ; \mathrm{y}=$ 302,2). Parte media de la Fm. Guezzart. Havlíček (1970, 1971), Destombes (2000).

- 1881: Entre Hassi Brahim y Akka (Tetla de Tagmoute*, Tata**: $x=240,55 ; y=302,4)$. Techo de la Fm. BouZeroual. Destombes (2000).

- 1886: Entre Hassi Brahim y Akka (Tetla de Tagmoute*, Tata** $x=240,55 ; y=302,4)$. Parte alta de la Fm. Bou-Zeroual. Destombes (2000)

- 1890: O de Akka (Akka***: $x=201,6 ; y=258,5)$. Tercio inferior de la Fm. Tachilla. Destombes (2000).

- 1896: Oeste de Akka, Región de Akka-Tata (Akka***: $x=212,2 ; y=266,1)$. Techo de la Fm. Guezzart. Havlíček (1970, 1971), Destombes (2000).

- 1897: O de Akka (Akka***: x=212,9; y= 266,05). Fm. Ouine-Inirne. Destombes (2000).

- 1898: Oeste de Akka (Akka***: $x=213,2 ; y=266)$. Parte media de la Fm. Izegguirene. Destombes (1972, 2000).

- 1906: Tisgui-Cheikh, al NO de Foum el Hassane (Taghjijt* $^{*}$ Foum-el-Hassane $\left.{ }^{* *}: x=147,3 ; y=240,2\right)$. Techo de la Fm. Tachilla. Havlíček (1971), Destombes (2001).

- 1908: Jbel Irhir n'Ouadou, entreAmalou n'Boufsass y el Adrar Yousquerht, Bani plegado (Anti-Atlas occidental) (Taghjijt $^{\star}$, Foum el Hassane $\left.{ }^{\star *}: \mathrm{x}=146 ; \mathrm{y}=239,7\right)$. Fm. Izegguirene. Babin y Destombes (1990), Destombes (2001).

- 1909: Jbel Annoumes-Tintichchad (= Assif Tarouras), al NO de Assa (Fask*, Taidalt $\left.{ }^{\star *}: x=146,0 ; y=240,0\right)$. Fm. Guezzart. Destombes (2001).

-1910-1912: NO de Foum el Hassane (= Fam el Hisn), entre Amalou n'Boufsass y el Adrar Yousquerht (Taghjijt* $^{*}$ Foum el Hassane ${ }^{\star *}$ : $x=146,0 ; y=240,1 / 240,15$ y 240,2 respectivamente). Lentejones calcáreos cerca del techo de la Fm. Bou-Zeroual. Destombes (2001).

- 1924: Jbel Annoumes-Tintichchad (= Assif Tarouras), al NO de Assa (Fask ${ }^{*}$, Taidalt** $\left.x=98,2 ; y=196,0\right)$. Fm. Guezzart. Havlí̌cek (1970, 1971), Destombes (2001, 2002). 
- 1925: Jbel Annoumes-Tintichchad (=Assif Tarouras), al NO de Assa (Fask*, Taidalt $\left.{ }^{* *}: x=98,25 ; y=196,0\right)$. Techo de la Fm. Bou-Zeroual. Destombes $(2001,2002)$.

-1933: Kheneg M'Karz, Anti-Atlas occidental (Goulimine $^{*}$, Taidalt $\left.{ }^{* *}: x=1072,9 ; y=761,7\right)$. Parte alta de la Fm. Izegguirene. Destombes (2002).

- 1934: Kheneg M'Karz, Anti-Atlas occidental (Goulimine $^{*}$, Taidalt $\left.{ }^{\star *}: x=1072,85 ; y=761,7\right)$. Parte alta de la Fm. Izegguirene. Destombes (2002).

- 1937: Jbel Segdit (Bani plegado, Anti-Atlas centrooccidental) (Fask* ${ }^{*}$ Taidalt ${ }^{* *}: x=1128,35 ; y=776$ ). Fm. Izegguirene (Destombes, 2002).

- 1938: Jbel Segdit (Bani plegado, Anti-Atlas centrooccidental) (El Borj 1:50.000, $x=1128,05$; y = 776). Fm. Ouine-Inirne, horizonte atribuido previamente a la Fm. Guezzart (Babin y Destombes, 1990: Fig. 2).

- 1939: Jbel Segdit (Bani plegado, Anti-Atlas centrooccidental) (El Borj 1:50.000: $x=1128,25 ; y=776,2$ ). Probablemente en la Fm. Ouine-Inirne, localidad asignada previamente al techo de la "fm. Kissane" por Havlíček (1971).

- 1995: (Hassi Chamba**: $x=360,2 ; y=3249$ ). Grupo Primer Bani. Destombes (1983b).

- 1996: Gouiret Aniti, Daoura, al O de Hassi-Chamba

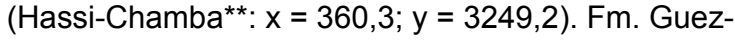
zart. Havlíceek (1971), Destombes (1983b).

- 1997: (Hassi Chamba**: $x=360,4 ; y=3246,8$ ). Parte baja del Grupo Primer Bani, probablemente tramo elevado en la Fm. Taddrist o base de la Fm. Bou-Zeroual. Destombes (1983b).

- 2011: Foum ez Zidiya (= Zeidiya), Macizo de Ougarta, NO de Argelia (Kerzaz ${ }^{* *}: x=655,4 ; y=3260$ ). Parte media de la Fm Guezzart. Babin y Destombes (1990).

- 2028: Jorf ed Dal, Macizo de Taouz y Tafilalt occidental (Erfoud*, Tafilalt**: $x=586 ; y=95,3)$. Fm. Tachilla. Destombes (1987).

- 2138: Jbel Ouarzemimen, cerca de Assaka, Macizo de Tachilla (Tiznit*: $x=99,3$; y = 306,7). Base Fm. Tachilla. Elaouad-Debbaj (1987).

- 2169: Paso de montaña de Tizi n'Tanekfoult, en Aharsi n'Tafounast (Tazzarine*, Jbel Sarhro**: $x=451$; y = 412,4). Parte superior de la Fm. Ouine-Inirne. El punto 2169 bis, se sitúa algunos metros por encima del horizonte 2169 en la misma localidad. Elaouad-Debbaj (1987).

- 2405: Sur de Ammar, al N de Alnif (Alnif*, Todrha**: $x$ $=517,4 ; \mathrm{y}=64,8)$. Fm. Tachilla?. Elaouad-Debbaj (1987).

- 2433: escombros de un pozo de agua, cerca de Zaouia-Tafechtna al E de Agdz (Tazzarine*, Jbel Sarhro**: $x=449,2 ; y=408,3)$. Techo de la Fm. Izegguirene. Elaouad-Debbaj (1987).

- 2479: Jbel Izegguirene (Tazzarine*, Jbel Sarhro**: $x=471,7 ; y=423,6)$. Formación Izegguirene. Destombes (inédito).
- PF 691: R e g i ón de Akka-Tata (Anti-Atlas centrooccidental), Jbel Bani, sin coordenadas precisas (Muestras colectadas por Petrofina). Probable base del Grupo Primer Bani (Fm. Taddrist). Babin y Destombes (1990).

Nota: Para las descripciones geográficas hemos utilizado la transcripción francesa de las voces árabes (por ejemplo Jbel en lugar de Djebel, Jebel o Yébel -montaña o alineación montañosa-; Oued en lugar de Ued, Uad o Uadi río o cauce intermitente-; Tafilalt en lugar de Tafilete o Tafilalet -región en el Anti-Atlas oriental-). La razón estriba en su mejor concordancia con la toponimia original de los mapas utiliza-dos para fijar las coordenadas de cada yacimiento.

\section{Referencias bibliogra' ficas}

Babin, C., Destombes, J., 1990. Les Mollusques Bivalves et Rostroconches ordoviciens de l'Anti-Atlas marocain : Intérêt paléogéographique de leur inventaire. Géologie Méditerranéenne 17, 243-261.

Bassett, M.G., Owens, R.M., 1996. Discussion on a revision of Ordovician Series and Stage divisions from the historical type area (with a reply by R.A. Fortey, D.A.T. Harper, J.K. Ingham, A.W. Owen \& A.W.A. Rushton). Geological Magazine 133 (6), 767-772.

Beisswenger, M., 1994. A calcichordate interpretation of the new mitrate Eumitrocystella savilli from the Ordovician of Morocco. Paläontologische Zeitschrift 68, 443-462.

Bergström, S.M., Finney, S.C., Chen, X., Pälsson, C., Wang, Z.h., Grahn,Y., 2000. A proposed global boundary stratotype for the base of the Upper Series of the Ordovician System. The Fagelsang Section, Scania, Southern Sweden. Episodes 23 (2), 102-109.

Berry, W.B.N., 1995. Plate motions, oceanographic change and ecologic controls: influence on corelation of the base of the Llanvirn Series, Ordovician System. Newsletters on Stratigraphy 32, 45-55.

Bettley, R.M., Fortey, R.A., Siveter, D.J., 2001. High-resolution correlation of Anglo-Welsh Middle to Upper Ordovician sequences and its relevance to international chronostratigraphy. Journal of the Geological Society, London 158, 937-952.

Bigot, A., Dubois, J., 1931. Sur la présence de l'Ordovicien dans l'AntiAtlas marocain. Comptes Rendus de l'Académie des Sciences, Paris 193, 282-283.

Bouc `ek, B., 1973. Lower Ordovician graptolites of Bohemia. Praha. Academia.

Brenchley, P.J., Romano, M., Gutiérrez-Marco, J.C., 1986. Proximal and distal Hummocky cross-stratified facies on a wide Ordovician shelf in Iberia. In: Knight, R.J., McLean, J.R. (Eds.), Shelf sands and sandstones. Canadian Society of Petroleum Geologists, Memory 11, 241-255.

Chauvel, J., 1966. Echinodermes de l'Ordovicien du Maroc. Cahiers de Paléontologie, 1966. CNRS, Paris.

Chauvel, J., 1969. Données nouvelles sur le genre Destombesia CHAUVEL (Echinoderme Cystoïde. Ordovicien de l'Anti-Atlas marocain). Notes et Mémoires du Service Géologique du Maroc 29 (213), 25-31. Chauvel, J.,

1971. Les échinodermes carpoïd e s d u P a I éozoïque inférieur marocain. Notes et Mémoires du Service Géologique du Maroc 31 (237), 49-60.

Chauvel, J., 1978. Compléments sur les Echinodermes du Paléozoïque marocain (Diploporites, Eocrinoïdes, Edrioastéroïdes). Notes et Mémoires du Service Géologique du Maroc 39 (272), 27-78.

Chen, X., Bergström, S.M. (Eds.), 1995. The base of the austrodentatus Zone as a level for global subdivision of the Ordovician System. Palaeoworld 5, 1-117.

Choubert, G., 1942. Constitution et puissance de la série primaire de l'AntiAtlas. Comptes Rendus de l'Académie des Sciences, Paris 215, $445-447$.

Choubert, G., 1943. L'Acadien et l'Ordovicien de l'Anti-Atlas. Comptes Rendus de l'Académie des Sciences, Paris 216, 158-160. 
Choubert, G., 1952. Geologie du Maroc. Fascicule I, $2^{\mathrm{e}}$ partie : Histoire géologique du Domaine de l'Anti-Atlas. Notes et Mémoires du Service Géologique du Maroc 100, 75-195.

Cocks, L.R.M., Fortey, R.A., 1988. Lower Palaeozoic facies and faunas around Gondwana. In: Audley-Charles, M.G., Hallam, A. (Eds.), Gondwana and Tethys. Geological Society Special Publication 37, 183-200.

Cocks, L.R.M., Fortey, R.A., 1990. Biogeography of Ordovician and Silurian faunas. In: McKerrow, W.S., Scotese, C.R. (Eds.), Palaeozoic Palaeogeography and Biogeography. Geological Society Memory 12, 97-104.

Cornée, J.J., Destombes, J., 1991. L’Ordovicien de la partie W du Massif ancien du Haut-Atlas occidental (Maroc hercynien). Geobios 24 (4), 403-415.

Couto, H., Piçarra, J.M., Gutiérrez-Marco, J.C., 1997. El Paleozoico del Anticlinal de Valongo (Portugal). In: Grandal d'Anglade, A., GutiérrezMarco, J.C., Santos Fidalgo, L. (Eds.), Comunicaciones XIII Jornadas de Paleontología y $\mathrm{V} R$ e $\mathrm{u} \mathrm{n}$ i ón Internacional PIGC 351 (ISBN 84-605- 6825-3), pp. 270-290.

Cramer, F.H., Díez, M.C.R., 1975. Thermal alteration of palynomorphs indicates absence of liquid hydrocarbons in Djebel Bani, Southern Morocco. Neues Jahrbuch für Geologie und Paläontologie, Monatshefte 9 , 513-516.

Cripps, A.P., 1990. A new stem craniate from the Ordovician of Morocco and the search for the sister group of craniata. Zoological Journal of the Linnean Society, London 100, 27-71.

Destombes, J., 1960. Stratigraphie de l'Ordovicien de la partie occidentale du Jbel Bani et du Jbel Zini.Anti-Atlas occidental (Maroc). Bulletin de la Société Géologique de France 7 (2), 747-751.

Destombes, J., 1966. Quelques Calymenina (Trilobitae) de l'Ordovicien moyen et supérieur de l'Anti-Atlas (Maroc). Notes et Mémoires du Service Géologique du Maroc 26 (188), 33-53.

Destombes, J., 1972. Les trilobites du sous-ordre des Phacopina de l'Ordovicien de l'Anti-Atlas (Maroc). Notes et Mémoires du Service Géologique du Maroc 240, 1-114.

Destombes, J., 1983a. Notice explicative (Cambrien moyen, Ordovicien, base du Silurien) de la Carte géologigue du Maroc au $200000^{\mathrm{e}}$ de l'Anti-Atlas marocain. Chapitre A : Feuilles Zagora-Coude du DraHamada du Dra. Rapport Interne du Service de la Carte géologique du Maroc, Rabat (inédit).

Destombes, J., 1983b. Notice explicative (Ordovicien, base du Silurien) de la Carte géologique du Maroc au 200 000e de l'Anti-Atlas marocain. Chapitre B : Feuilles Bou-Haiara--Zegdou--Hassi-Chamba. Rapport Interne du Service de la Carte géologique du Maroc, Rabat (inédit).

Destombes, J., 1983c. Notice explicative (Cambrien moyen, Ordovicien, base du Silurien) de la Carte géologique du Maroc au 200000 e de l'Anti-Atlas marocain. Chapitre C : F euilles Dadès-Sagrhro. Rapport Interne du Service de la Carte géologique du Maroc, Rabat (inédit).

Destombes, J., 1985. Notice explicative (Cambrien moyen, Ordovicien, base du Silurien) de la Carte géologique du Maroc au 200 000e de l'AntiAtlas marocain. Chapitre D : Feuilles Todhra-Maïder. Rapport Interne du Service de la Carte géologique du Maroc, Rabat (inédit).

Destombes, J., 1987. Notice explicative (Cambrien moyen, Ordovicien, base du Silurien) de la Carte géologique du Maroc au 200 000e de l'Anti-Atlas marocain. Chapitre E: Feu illes Tafilalt-Taouz. Rapport Interne du Service de la Carte géologique du Maroc, Rabat (inédit).

Destombes, J., 1988. Notice explicative (Cambrien moyen, Cambrien supérieur, Ordovicien, base du Silurien) de la Carte géologique du Maroc au $200000^{\mathrm{e}}$ de l'Anti-Atlas marocain. Chapitre F: Feuilles Teloued Sud, Ouarzazate, Alougoum, Agadir-Tissinnt. Rapport Interne du Service de la Carte géologique du Maroc, Rabat (inédit)

Destombes, J., 2000. Notice explicative (Ordovicien, base du Silurien) de la Carte géologique du Maroc au $200000^{\mathrm{e}}$ de l'Anti-Atlas marocain. Ch a p it re G:F euille Akka-Tafagount-Tata. Rapport Interne du Service de la Carte géologique du Maroc, Rabat (inédit).
Destombes, J., 2001. Notice explicative (Ordovicien-base du Silurien) de la

Carte géologique au $200000^{\mathrm{e}}$ du flanc sud de l'Anti-Atlas occidental et des plaines du Dra (Maroc). Chapitre $\mathrm{H}$ : $\mathrm{F}$ euille Foum el Hassane-Assa. Rapport Interne du Service de la Carte géologique du Maroc, Rabat (inédit).

Destombes, J., 2002. Notice explicative (Cambrien moyen, Ordovicien, base du Silurien) de la Carte géologique au $200000^{\mathrm{e}}$ de la « terminaison occidentale de l'Anti-Atlas. Région de Goulimine et du Dra inférieur » et de la Carte géologique au $100000^{\mathrm{e}}$ : Fask (Anti-Atlas occidental, Maroc). Chapitre I: F euille Goulimine - Dra inférieur au $200000^{\circ}$ Feuille Fask au $100000^{\circ}$. Rapport Interne du Service de la Carte géologique du Maroc, Rabat (inédit).

Destombes, J., Hollard, H., Willefert, S., 1985. Lower Palaeozoic rocks of Morocco. In: Holland, C.H. (Ed.), Lower Palaeozoic Rocks of the World, vol. 4. Lower Palaeozoic of north-western and west central Africa. John Wiley and Sons, Chichester, pp. 91-336.

Deunff, J., 1977. Un microplancton à Acritarches dans les schistes Ilanvirniens de l'Anti-Atlas (Zagora-Maroc). Notes et Mémoires du Service Géologique du Maroc 38 (268), 141-151.

El Bourkhissi, M., Sarmiento, G.N., 1997. Primeros conodontos ordovícicos del Anti-Atlas (Marruecos). In: Grandal d'Anglade, A., GutiérrezMarco, J.C., Santos Fidalgo, L. (Eds.), Comunicaciones XIII Jornadas de Paleontología y $\mathrm{V}$ Reunión Internacional PIGC 351 (ISBN 84-6056825-3). pp. 56-59.

El Hassani, A., El Wartiti, M., Zahraoui, M., Destombes, J., Willefert, S., 1988. Découverte d'une macrofaune arénigienne (Ordovicien inférieur) à trilobites et graptolithes dans la région de Rabat, Meseta côtière nord-occidentale (Maroc). Comptes Rendus de l'Académie des Sciences, Paris, sér. 2, 307, 1589-1594.

El Hassani, A., Destombes, J., Willefert, S., 1990. Le problème de l'ArenigLlanvirn (Ordovicien), la discordance calédonienne et la préparation de l'orogenèse hercynienne dans la région de Rabat-Tiflet (Maroc occidental). Bulletin de l'Institut Scientifique, Rabat 12 (de 1988), 27-45.

Elaouad-Debbaj, Z., 1984. Acritarches et Chitinozoaires de l'ArenigLlanvirn de l'Anti-Atlas (Maroc). Review of Palaeobotany and Palynology $43,67-88$.

Elaouad-Debbaj, Z., 1986. Chitinozoaires de la Formation du Ktaoua inférieur, Ordovicien Supérieur de l'Anti-Atlas (Maroc). Hercynica 2, 3555.

Elaouad-Debbaj, Z., 1987. Acritarches et Chitinozoaires de l'Ordovicien du Maroc. Systématique, biostratigraphie, corrélations. Thèse Université de Rennes I, C 471 (inédit).

Emig, C.C., Gutiérrez-Marco, J.C., 1997. Signification des niveaux à lingulidés à la limite supérieure du Grès Armoricain (Ordovicien, Arenig, Sud-Ouest de l'Europe). Geobios 30 (4), 481-495.

Fatká, O., Kraft, J., Kraft, P., Mergl, M., Mikulás, R., Storch, P., 1995. Ordovician of the Prague Basin: stratigraphy and development. Ordovician Odyssey. Book. Pacific Section Society for Sedimentary Geology 77, 241-244.

Finney, S.C., 1996. Potential GSSPs for Lower-Middle and Middle-Upper Ordovician Series boundaries. Abstracts 30th International Geological Congress, Beijing 2, 53

Fortey, R.A., 1984. Global earlier Ordovician transgressions and regressions and their biological implications. In: Bruton, D.L. (Ed.), Aspects of the Ordovician System. Palaeontological Contributions of the University of Oslo 295, 37-50.

Fortey, R.A., Beckly, A.J., Rushton, A.W.A., 1990. International correlation of the base of the Llanvirn Series, Ordovician System. Newsletters on Stratigraphy 22, 119-142.

Fortey, R.A., Harper, D.A.T., Ingham, J.K., Owen, A.W., Rushton, A.W.A., 1995. A revision of Ordovician series and stages from the historical type area. Geological Magazine 132, 15-30.

Fortey, R.A., Harper, D.A.T., Ingham, J.K., Owen, A.W., Parkes, M.A., Rushton, A.W.A., Woodcock, N.H., 2000. A revised correlation of Ordovician Rocks in the British Isles. Geological Society Special Report 24, $1-83$. 
Gutiérrez-Marco, J.C., 1986. Graptolitos del Ordovícico español. Tesis Doctoral, Universidad Complutense de Madrid, 3 vol.

Gutiérrez-Marco, J.C., 2000. Revisión taxonómica de "Echinosphaerites" murchisoni VERNEUIL and BARRANDE, 1855 (Echinodermata, Diploporita) del Ordovícico Medio centroibérico (España). Geogaceta 27, 83-86.

Gutiérrez-Marco, J.C., Baeza Chico, E., 1986. Descubrimiento de Aristocystites metroi PARSLEY and PROKOP, 1990 (Echinodermata, Diploporita) en el Ordovícico Medio centroibérico (España). Geogaceta 20, 225-227.

Gutiérrez-Marco, J.C., Rábano, I., 1987. Paleobiogeographical aspects of the Ordovician mediterranean faunas. Geogaceta 2, 24-26.

Gutiérrez-Marco, J.C., Rábano, I., Prieto, M., Martín, J., 1984. Estudio bioestratigráfico del Llanvirn y Llandeilo (Dobrotiviense) en la parte meridional de la Zona Centroibérica. Cuadernos de Geología I b érica 9 , 289-321.

Gutiérrez-Marco, J.C., Rábano, I., San José, M.A., Herranz, P., Sarmiento, G.N., 1995. Oretanian and Dobrotivian stages vs. "LlanvirnLandeilo" Series in the Ordovician of the Iberian Peninsula. In: Coo-per, J.D., Droser, M.L., Finney, S.C. (Eds.), Ordovician Odyssey, 77. Book, Pacific Section Society for Sedimentary Geology, pp. 55-59.

Gutiérrez-Marco, J.C., Albani, R., Aramburu, C., Arbizu, M., Babin, C., García-Ramos, J.C., Méndez-Bedia, I., Rábano, I., Truyols, J., Vannier, J., Villas, E., 1996. Bioestratigrafía d e I a F o r m a c i ón Pizarras del Sueve (Ordovícico Medio) en el sector septentrional de la Escama de Laviana-Sueve (Zona Cantábrica, N de España). Revista Española de Paleontología 11 (1), 48-74.

Gutiérrez-Marco, J.C., Schallreuter, R., El Bourkhissi, M., Hinz-Schallreuter, I., 1997. Identificación del género Reuentalina (ostrácodo Palaeocopa) en el Ordovícico Medio del Anti-Atlas central marroquí. In: Grandal d'Anglade, A., Gutiérrez-Marco, J.C., Santos Fidalgo, L. (Eds.), Comunicaciones XIII Jornadas de Paleontología y $\mathrm{V}$ Reunión Internacional PIGC 351 (ISBN 84-605-6825-3). pp. 80-83.

Gutiérrez-Marco, J.C., Aramburu, C., Arbizu, M., Bernárdez, E., Hacar Rodríguez, M.P., Méndez-Bedia, I., Montesinos López, R., Rábano, I., Truyols, J., Villas, E., 1999a -. Revisión bioestratigráfica de las pizarras del Ordovícico Medio en el noroeste de España (Zonas Cantábrica, Asturoccidental-leonesa y Centroibérica septentrional). Acta Geologica Hispanica 34 (1), 3-83.

Gutiérrez-Marco, J.C., Rábano, I., Sarmiento, G.N., Aceñolaza, F.G., San José, M.A., Pieren, A.P., Herranz, P., Couto, H.M., Piçarra, J.M., 1999b. Faunal dynamics between Iberia and Bohemia during the Oretanian and Dobrotivian (late Middle-earliest Upper Ordovician), and biogeographic relations with Avalonia and Baltica. Acta Universitatis Carolinae. Geologica 43, 487-490.

Gutiérrez-Marco, J.C., Robardet, M., Rábano, I., Sarmiento, G.N., San José Lancha, M.A., Herranz Araújo, P., Pieren Pidal, A.P., 2002. Chapter 4: Ordovician. In: Moreno, T., Wibbons, W. (Eds.), The Geology of Spain. Geological Society Special Publications, London [párution in septembre 2002].

Hammann, W., 1974. Phacopina und Cheirurina (Trilobita) aus dem Ordovizium von Spanien. Senckenbergiana lethaea 53, 1-151.

Hammann, W., Rábano, I., Gutiérrez-Marco, J.C., 1986. Morfología funcional del exoesqueleto del género Selenopeltis HAWLE and CORDA, 1847 (Trilobita, Odontopleurida ; Ordovícico). Paleontologia i Evolució, Sabadell 20, 203-211.

Hamoumi, N., 2001. The First Bani Group (Llandeilo) of central Anti-Atlas: an example of tide dominated deltaic sedimentation. In: Hamoumi, N. (Ed.), Official Business Meeting and Field excursion of the Subcommisssion on Ordovician Stratigraphy, Rabat, 29.

Havlíček, V., 1970. Heterorthidae (Brachiopoda) in the Mediterranean Province. Sborník geologickych ved, Paleontologie 12, 7-39.

Havlíček, V., 1971. Brachiopodes de l'Ordovicien du Maroc. Notes et Mémoires du Service Géologique du Maroc 230, 1-135.

Havlíček, V., Fatká, O., 1992. Ordovician of the Prague Basin (Barrandian area, Czechoslovakia). In: Webby, B.D., Laurie, J.R. (Eds.), Global Perspectives on Ordovician Geology. Balkema, Rotterdam, pp. 461-472.
Havlíček, V., Marek, L., 1973. Bohemian Ordovician and its international correlation. Casopis pro mineralogii a geologii 18, 225-232.

Havlíček, V., Vane`k, J., 1996. Dobrotivian/Berounian boundary interval in the Prague Basin with a special emphasis on the deepest part of the trough (Ordovicican, Czech Republic). Vestník Ceského geologického ústavu 71, 225-243.

Havlíček, V., Vane`k, J., Fatká, O., 1994. Perunica microcontinent in the Ordovician (its position within the Mediterranean Province, series division, benthic and pelagic associations). Sborník geologickych ved. Geologie 46, 23-56.

Henry, J.L., 1980. Trilobites ordoviciens du Massif Armoricain. Mémoires de la Société Géologique et Minéralogique de Bretagne 22, 1-250. Henry, J.L., Destombes, J., 1991. Un biofaciès à Trilobites Homalonotidae dans l'Ordovicien de la marge nord-gondwanienne: implications paléobiologiques et paléogéographiques. Lethaia 24, 249-253.

Henry, J.L., Mélou, M., Nion, J., Paris, F., Robardet, M., Skevington, D., Thadeu, D., 1976. L'apport de Graptolites de la Zone à G. teretiusculus dans la datation de faunes benthiques lusitano-armoricaines. Annales de la Société Géologique du Nord 96, 275-281.

Horný, R.D., 1997a. Quasisinuites rapax gen. et sp. n., a newsinuate cyrtonellid mollusc (Class Tergomya) with involute shell from the Ordovician of Morocco. Vestník Ceského Geologického ústavu 72, 345-350.

Horný, R.D., 1997b. Ordovician Tergomya and Gastropoda of theAnti-Atlas (Morocco). Sborník N árodního muzea, rada B 53, 37-78 [Prírodní vedy].

International Union of Geological Sciences (IUGS) 2000. International Stratigraphic Chart and Explanatory note (compiled by J. RemaneDivision of Earth Sciences, Unesco, 1-16.

Jefferies, R.P.S., Lewis, D.N., 1978. The English Silurian fossil Placocystites forbesianus and the ancestry of the vertebrates. Philosophical Transactions of the Royal Society of London [B] 282, 205-323. Kraft, J., 1974. Graptolites from the "Drahous" locality near Rokycany

(Sárka Formation - Llanvirnian of the Ordovician of the Barrandian). Folia Musei Rerum Naturalium Bohemiae Occidentalis 3, 1-15 [Geologica], PIzen

Kraft, J., Kraft, P., 1993. The Arenig/Llanvirn boundary (Ordovician) in the Prague Basin (Bohemia). Journal of the Czech Geological Society 38, 189-192.

Kraft, J., Kraft, P., 1995. Biostratigraphy of the Klabava and Šárka formations (Bohemia, Lower Ordovician) - A brief overview of new investigations. Acta Universitatis Carolinae, Geologica 1-2 (de 1992), 23-29.

Kraft, J., Kraft, P., 1999a. Graptolite biostratigraphy of the Lower and Middle Ordovician of Bohemia. Acta Universitatis Carolinae. Geologica 43, 33-36.

Kraft, J., Kraft, P., 1999b. Graptolite biozones of the Bohemian Lower and Middle Ordovician and their historical development. Journal of the Czech Geological Society 44, 53-62.

Kraft, P., Kraft, J., 2000. Faunal changeover and diversity trends on the Arenigian/Llanvirnian boundary in the Bohemian Ordovician. Geological Society of Australia. Abstracts 61, 51-52.

Lefebvre, B., 2000. A new mitrate (Echinodermata, Stylophora) from the Tremadoc of Shropshire (England) and the origin of Mitrocystitida. Journal of Paleontology 74 (5), 890-906.

Lefebvre, B., Vizcaïno, D., 1999. New Ordovician cornutes (Echinodermata, Stylophora) from Montagne Noire y Brittany (France) and revision of the order Cornuta Jaekel 1901. Geobios 32 (3), 421-458.

Legrand, P., 1964. Un Graptolite intéressant de l'Arenigien supérieur du Sahara algérien : Didymograptus $v$-fractus wieli nov. subsp. Compte Rendu Sommaire des Séances de la Société Géologique de France 1964 (9), 360-363.

Maletz, J., 1992. The Arenig/Llanvirn boundary in the Quebec Appalachians. Newsletters on Stratigraphy 26, 49-64.

Maletz, J., 1997. Graptolites from the Nicholsonograptus fasciculatus and Pterograptus elegans Zones (Abereiddian, Ordovician) of the Oslo region, Norway. Greifswalder Geowissenschaftliche Beiträge 4, 5-98. 
Maletz, J., Mitchell, C.E., 1995. Atlantic versus Pacific province graptolite faunas: where is the big difference?. Graptolite News, Buffalo 8, 43-45. Marek, L., 1983. The Ordovician hyoliths of Anti-Atlas (Morocco). Sborník Národního muzea, rada B 39, 1-36 [Prírodní vedy]

Mélou, M., Oulebsir, L., Paris, F., 1999. Brachiopodes et chitinozoaires ordoviciens dans le NE du Sahara algérien : implications stratigraphiques et paléogeographiques. Geobios 32 (6), 823-839. Mitchell,

C.E., Chen, X., Bergström, S.M., Zhang, Y-d, Wang, Z-h,

Webby, B.D., Finney, S.C., 1997. Definition of a global boundary stratotype for the Darriwilian Stage of the Ordovician System. Episodes 20, 158-166.

Obut, A.M., Sennikov, N.V., 1987. Oepikograptus, a peculiar genus of Middle Ordovician diplograptids (graptolites). In: Kolobova, I.M., Hosatski, L.I. (Eds.), Annual of the All-Union Paleontological Society, 30. Nauka, Leningrad, pp. 192-198.

Oulebsir, L., Paris, F., 1995. Chitinozoaires ordoviciens du Sahara algérien : biostratigraphie et affinités paléogéographiques. Review of Palaeobotany and Palynology 86, 49-68.

Paris, F., 1990. The Ordovician chitinozoan biozones of the Northern Gondwana Domain. Review of Palaeobotany and Palynology 66, 181-209.

Paris, F., 1996. Chapter 17. Chitinozoan biostratigraphy and palaeoecology. In: Jansonius, J., McGregor, D.C. (Eds.), Palynology: principles and applications, 2. American Association of Stratigraphic Palynologists Foundation, Salt Lake City, pp. 531-552.

Paris, F., 1999. Palaeobiodiversification of Ordovician chitinozoans from northern Gondwana. Acta Universitatis Carolinae, Geologica 43 (1-2), 283-286.

Paris, F., Verniers, J., Achab, A., Albani, R., Ancilletta, A., Asselin, E., Chen, X-h, Fatka, O., Grahn, Y., Molyneux, S., Nolvak, J., Samuels-son, J., Sennikov, N.V., Soufiane, A., Wang, X-f, Winchester-Seeto, T., 1999. Correlation of Ordovician regional chitinozoan biozonations. Acta Universitatis Carolinae, Geologica 43 (1-2), 291-294.

Paul, C.R.C., Kesling, R.V., 1968. Echinodermes de l'Ordovicien du Maroc by Jean Chauvel, 1966 [Review]. Journal of Paleontology 42, 245-247.

Philippot, A., 1950. Les Graptolites du Massif armoricain. Étude stratigraphique et paléontologique. Mémoires de la Société Géologique et Minéralogique de Bretagne 8, 1-295.

Piqué, A., Cornée, J.J., Müller, J., Roussel, J., 1991. The moroccan hercynides. In: Dallmeyer, R.D., Lécorché, J.P. (Eds.), the West African Orogens and Circum-Atlantic correlatives. Springer-Verlag, Heidelberg, pp. 229-263.

Robillard, A., 1935. Révision des graptolites ordoviciens du Massif armoricain. Compte Rendu Sommaire des Séances de la Société Géologique et Minéralogique de Bretagne 1 (4), 3-7.

San José, M.A., Rábano, I., Herranz, P., Gutiérrez-Marco, J.C., 1992. El Paleozoico inferior de la Zona Centroibérica meridional. In: GutiérrezMarco, J.C., Saavedra, J., Rábano, I. (Eds.), Paleozoico Inferior de Ibero-América, Universidad de Extremadura, pp. 505-521.
Schallreuter, R., Kruta, M., Marek, L., 1996. Ordovician (Dobrotivá Formation) ostracodes and trilobites from Ejpovice (Bohemia) and their relations to faunas of northern and western Europe. Paläontologische Zeitschrift 70, 439-460.

Termier, G., Termier, H., 1950a. Paléontologie Marocaine. Tome II, Invertébrés d e I'Ėre Primaire. Fascicule II, Bryozoaires et Brachiopodes. In: Hermann, Cie (Eds.), Paris, ser. Actualités Scientifiques et Industrielles, y Notes et Mémoires du Service Géologique du Maroc 77, 1-253.

Termier, G., Termier, H., 1950b. Paléontologie Marocaine. Tome II, Invertébrés d e I 'Ère Primaire. Fascicule III, Mollusques. In: Hermann, Cie (Eds.), Paris, ser. Actualités Scientifiques et Industrielles, y Notes et Mémoires du Service Géologique du Maroc 78, 1-246.

Termier, G., Termier, H., 1950c. Paléontologie Marocaine. Tome II, Invertébrés d e I 'Ėre Primaire. Fascicule IV, Annélides, Arthropodes, Échinodermes, Conularides et Graptolithes. In: Hermann, Cie (Eds.), Paris, ser. Actualités Scientifiques et Industrielles, y Notes et Mémoires du Service Géologique du Maroc 79, 1-279.

Termier, H., 1936. Études géologiques sur le Maroc Central et le Moyen Atlas septentrional (en 4 vol.). Tome III. Paléontologie, Petrographie. Notes et Mémoires du Service des Mines et de la Carte géologique du Maroc 33 (3), 1087-1421.

Termier, H., Termier, G., 1947. Les principaux niveaux paléontologiques de l'Ordovicien marocain. Compte Rendu Sommaire des Séances de la Société Géologique de France 13, 254-256.

Ubaghs, G., 1979. Trois Mitrata (Echinodermata: Stylophora) nouveaux de l'Ordovicien de Tchécoslovaquie. Paläontologische Zeitschrift 53 (1/2), 98-119.

Ubaghs, G., 1994. Échinodermes nouveaux (Stylophora, Eocrinoidea) de l'Ordovicien inférieur de la Montagne Noire (France). Annales de Paléontologie 80, 107-141.

Vannier, J., 1986. Ostracodes Palaeocopa de l'Ordovicien (Arenig-Caradoc) ibéro-armoricain. Palaeontographica (A) 193, 145-218.

Vidal, M., 1996. Biofaciès à trilobites dans l'Ordovicien inférieur de l'AntiAtlas, Maroc : paléoenvironnements et paléobiogéographie. Thèse Université de Rennes I (inédit).

Vidal, M., 1998a. Le modèle des biofaciès à trilobites : un test dans l'Ordovicien inférieur de l'Anti-Atlas, Maroc. Comptes Rendus de l'Académie des Sciences, Paris, Sciences de la terre et des planètes 327 , 327-333.

Vidal, M., 1998b. Trilobites (Asaphidae et Raphiophoridae) de l'Ordovicien inférieur de l'Anti-Atlas, Maroc. Palaeontographica (A) 251, 39-77. Webby, B.D., 1998. Steps toward a global standard for Ordovician stratigraphy. Newsletters on Stratigraphy 36, 1-33.

Willefert, S., Charrière, A., 1990. Les formations à Graptolithes des boutonnières du Moyen-Atlas tabulaire (Maroc). Géologie Méditerranéenne 17 (3-4), 279-299. 